\title{
Geoquímica y geocronología U-Pb de la cuarzodiorita de Sabanalarga y el gabro de Santa Fe, Colombia
}

\author{
Geochemistry and U-Pb geochronology of the Sabanalarga quartz-diorite and Santa Fe gabbro, \\ Colombia
}

Juan Pablo Zapata-Villada ${ }^{1, *}$, Wilmer Giraldo², Gabriel Rodríguez ${ }^{1}$, Mauro Cesar Geraldes², Milton Obando

${ }^{1}$ Servicio Geológico Colombiano, Calle 75, N ${ }^{\circ}$

79A-51, 50034, MDE, Antioquia, Colombia.

${ }^{2}$ Faculdade de Geologia ,Universidade do Estado do Rio de Janeiro, Rua São Francisco Xavier, $524-4^{\circ}$ e $2^{\circ}$ andar/Bloco A Maracanã, 20.550-900, Rio de Janeiro, Brasil.

* Autor para correspondencia: (J. P. Zapata Villada)juanp.zapatav@gmail.com
La revisión por pares es responsabilidad de la Universidad Nacional Autónoma de México.

\section{RESUMEN}

Durante el Cretáceo Superior, el margen noroccidental de Suramérica se caracterizó por presentar un ambiente tectónico complejo, representado por la acreción de múltiples terrenos y la generación de varios eventos magmáticos. La cuarzodiorita de Sabanalarga y el Gabro de Santa Fe, anteriormente descritos como una única unidad denominada "Batolito de Sabanalarga", presentaban múltiples diferencias entre sí y hoy son considerados dos plutones independientes, exponiendo dos de los eventos magmáticos del cretáceo superior. Ambos plutones emplazados en cortezas de diferente afinidad; el Gabro de Santa Fe emplazado en corteza tipo Plateau y arco de islas, mientras que la cuarzodiorita de Sabanalarga es emplazada en corteza continental del Complejo Cajamarca. Los análisis químicos de roca total realizados, presentaron anomalías de $\mathrm{Nb}-\mathrm{Ti}$, patrones de HFSE y REE en los diagramas multielementales característicos de rocas generadas en ambientes de subducción. El gabro de Santa Fe presenta características adakiticas no presentes en la cuarzodiorita de Sabanalarga. El bajo contenido $\mathrm{Zr}$ y relaciones $(\mathrm{La} / \mathrm{Yb}) \mathrm{n}$ vs $\mathrm{Sr} / \mathrm{Y}<10$ sugieren que el magma del Gabro de Santa Fe fue formado en ambiente oceánico, contrario a la cuarzodiorita de Sabanalarga con alto $\mathrm{Zr}$ y relaciones $(\mathrm{La} / \mathrm{Yb}) \mathrm{n}$ vs $\mathrm{Sr} / \mathrm{Y}>10$ que sugieren para este magma un origen en un ambiente continental. Se realizaron análisis U-Pb LA-ICP-Ms para ambos intrusivos: el Gabro de Santa Fe presentó edades entre 78.4 y 81.8 Ma y la cuarzodiorita de Sabanalarga edades entre 71.5 y $76.7 \mathrm{Ma}$. A la luz de los nuevos datos geoquímicos y geocronológicos se sugiere en este trabajo que el Gabro de Santa Fe y la cuarzodiorita de Sabanalarga son dos cuerpos diferentes sin relación temporal y cuya relación espacial es todavía debatible. Para el ambiente de formación de estos plutones se sugiere un modelo de doble subducción tipo Molucca.

\section{ABSTRACT}

During the Upper Cretaceous the northwestern margin of South America was characterized by a complex tectonic environment represented by the accretion of multiple terranes and the generation of varied magmatic events. The Sabanalarga quartz-diorite and the Santa Fe Gabbro previously described as a single body called Sabanalarga Batholith, present multiple differences among themselves and today are considered two independent plutons, representing two of the upper Cretaceous magmatics events. Both plutons intrude crusts of different affinity; The Santa Fe Gabbro intrudes a Plateau-type and island arc crust while the Sabanalarga quartz-diorite intrude into continental crust. The carried total rock chemical analysis showed anomalies of $\mathrm{Nb}$-Ti, patterns of HFSE and REE in the multielemental diagrams indicatives of rocks generated in subduction environments. The Santa Fe Gabbro presents adakitic characteristics that are not present in the Sabanalarga quartz-diorite. The low Zr content and relations ( $\mathrm{La} / \mathrm{Tb}$ ) n vs $\mathrm{Sr} /$ $r<10$ suggest that the Santa Fe Gabbro magma was formed in an oceanic environment, contrary to the Sabanalarga quartz-diorite with high $Z r$ and relationships $(\mathrm{La} / \mathrm{Yb}) \mathrm{n}$ vs $\mathrm{Sr} / \mathrm{Y}>10$ who suggest an origin in a continental environment for this magma. U-Pb LA ICPMs were analyzed for both intrusives: Santa Fe Gabbro showed ages between 78.4 and 81.8 Ma and Sabanalarga quartz-diorite ages between 71.5 and 76.7 Ma. Due to the new geochemical and geochronological data, it is suggested that Santa Fe Gabbro and Sabanalarga quartz-diorite are two different bodies with no temporal relationship and whose spatial relationship is still debatable. Is suggested for the geological setting of formation for these plutons a double subduction model type Molucca.

Palabras clave: geoquímica, $\mathrm{U}-\mathrm{Pb}$, gabro de Santa Fe, cuarzodiorita de Sabanalarga.
Keywords: geochemistry, $U$ $P b$, Santa Fe de gabbro, Sabanalarga quartz-diorite. 


\section{Introducción}

La esquina noroccidental de Suramérica presenta una geología compleja; misma que se caracteriza por la interacción de las placas Suraméricana, Norteamericana, Nazca, Cocos y Caribe. Dicha interacción entre placas ha generado un mosaico de terrenos alóctonos altamente deformados (Jones et al., 1982) y acrecionados a la margen suramericana desde el Paleozoico hasta el Cenozoico (Restrepo y Toussaint, 1988); los cuales están denominados como Bloque Norandino (Suter et al., 2008).

Según Gómez et al., (2015), los terrenos que comprenden este bloque son, de occidente a oriente, Caribe, Arquía, Quebradagrande, Anacona, Tahamí y Chibcha (Figura 1). El terreno Caribe presenta afinidad oceánica; mientras que los que están al oriente (Anacona, Tahamí y Chibcha), presentan afinidad continental. El límite entre estos dos dominios geodinámicos está marcado por el sistema de fallas Cauca-Romeral y los terrenos Arquía y Quebradagrande. Este límite es considerado como un mosaico de presuntos terrenos de afinidades oceánicas o continentales (Restrepo et al., 2009), cuyas relaciones espaciotemporales están todavía en discusión (Restrepo et al., 2009; Villagómez et al., 201 1; Mora-Bohórquez et al., 2017).

A su vez, las unidades ígneas presentes en la zona de transición entre estos dos dominios fueron agrupadas en el denominado Batolito de Sabanalarga (Hall et al., 1972; Rodríguez y Zapata, 1995). Esta unidad fue definida como un batolito alargado con dirección norte-sur, con una extensión de aproximadamente $410 \mathrm{Km}^{2}$, y constituido por 3 facies (máfica-ultramáfica, intermedia y félsica) (González y Londoño, 2002), con edades ${ }^{40} \mathrm{Ar} /{ }^{39} \mathrm{Ar}$ (Hornblenda y Biotita) de aproximadamente 95 Ma (Gonzales et al., 1976; González y Londoño, 1998).

Respectivamente, el Batolito de Sabanalarga se encuentra dividido de norte a sur por la Falla Sabanalarga (Hall, 1972; Rodríguez et al., 2012a; Correa et al.,2018), Falla Romeral (Mejía y González, 1983) o Cauca-Almaguer (Nivia y Gómez, 2005). Nivia y Gómez (2005) separan esta unidad en dos: Gabro de Santa Fe y Cuarzodiorita de Sabanalarga. Al occidente de la Falla Sabanalarga, el Gabro de Santa Fe intruye las rocas de afinidad oceánica asociadas al terreno Caribe y presenta grandes xenolitos de la Granulita de Pantanillo (Cardona, 2010; Rodríguez et al., 2012b). Al oriente de la Falla Sabanalarga, la Cuarzodiorita de Sabanalarga intruye las rocas metamórficas de afinidad continental del terreno Tahamí. Este trabajo busca comprender la evolución de los cuerpos graníticos del occidente antioqueño durante el cretácico medio y tardío, a través de la definición de las relaciones entre las distintas unidades definidas como Gabro de Santa Fe y Cuazodiorita de Sabanalarga, sus unidades adyacentes y el sistema de fallas Cauca-Romeral, utilizando cartografia detallada, geoquímica y geocronología U-Pb (LA-ICP-MS).

\section{Metodología}

La presente investigación se desarrolló en dos grupos de trabajo, enmarcado cada uno en proyectos diferentes, pero con objetivos similares. El primero de estos fue una tesis de maestría realizada en la Universidad del Estado de Rio de Janeiro (UERJ) (Giraldo, W., 2017) ; auspiciada con el apoyo financiero del CAPES y el logístico de la Universidad Nacional de Colombia, Sede Medellín. El segundo grupo correspondió a la cartografía y muestreo de la plancha 130-Santa Fe de Antioquia a escala 1:50.000 (Correa et al., 2018), realizado por Grupo de Estudios Geológicos Especiales del Servicio Geológico Colombiano (SGG), Medellín.

El equipo de la UERJ realizó 40 análisis petrográficos de secciones delgadas preparadas en el Laboratorio Geológico de Preparación de Muestras (LGPA/UERJ) y 3 muestras adicionales del profesor Jorge Julián Restrepo. El grupo del SGC, analizó 39 muestras preparadas en el los laboratorios del SGG.

A 13 de estas muestras, se les realizaron análisis geoquímicos en el laboratorio del SGC sede Bogotá, con un espectrómetro de fluorescencia 

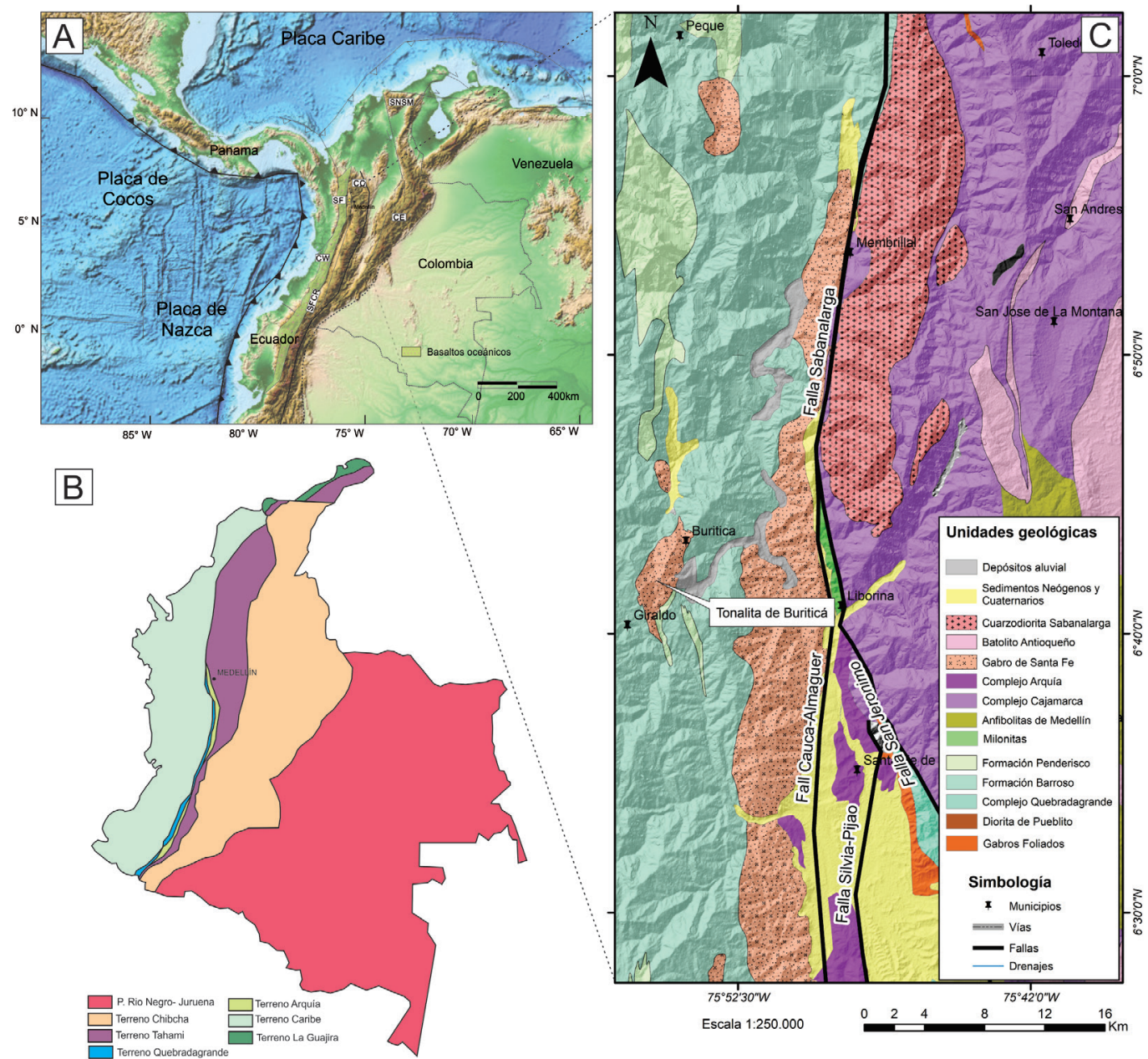

SFCR: Sistema de Fallas Cauca-Romeral. WC: Cordillera Occidental, CC: Cordillera Central, EC: Cordillera Oriental, SF: Santa Fe de Antioquía.

Figura 1 Localización, geología regional, abreviaturas y nomenclatura. A) Configuración tectónica de los Andes del Norte. B) Mapa de Terrenos (Modificado de Gómez et al., 2015). C) Mapa geológico regional (Modificado de Gómez et al., 2015).

de Rayos X Panalytical AXIOS Mineral. La cuantificación de los óxidos mayores se hizo en muestra fundida con metaborato y tetraborato de litio; mientras que la cuantificación de elementos menores fue en muestra prensada. Para el análisis de elementos traza, se usó un espectrómetro de masas con plasma inductivamente acoplado, ICP-MS, Perkin Elmer NEXION. Los diagramas petrográficos y geoquímicos se obtuvieron usando el software GCDkit de Janoušek et al., (2006).

Por su parte, el equipo UERJ colectó 14 muestras enfocadas a análisis geocronológicos 8 de éstas son discutidas en el presente trabajo. Fue utilizado el método UPb LA-ICP-MS en circones concentrados en el laboratorio geológico de preparación de muestras LGPA-UERJ, utilizando separación hidrodinámica y magnética. Los circones se seleccionaron manualmente con lupa binocular. De los montajes de granos de circón se adquirieron imágenes de catodoluminiscencia (CL) por medio de microscopio electrónico de barrido. Los análisis isotópicos de las muestras se llevaron a cabo en el Laboratorio multiusuario de medio ambiente y materiales MultiLab-UERJ, con el equipo Neptune plus - Laser Ablation Inductive ly Coupled Plasma Multi Colector Mass Spectrometry (LA-ICP-MS). Los mismos se realizaron con un diámetro de laser variable entre 20 y $30 \mu \mathrm{m}$, a una frecuencia de 8 $\mathrm{Hz}$ y energía variable entre el 35 y 40\%. El flujo de helio utilizado para el transporte de las muestras 
fue de $0.750 \mathrm{l} / \mathrm{m}$, y el flujo de argón utilizado por el ICP-MS fue de $0.800 \mathrm{l} / \mathrm{m}$. Se emplearon los patrones Zircon 91500 (Wiedenbeck et al., 2004) y GJ-1 (Jackson et al., 2014). Los blancos, patrones y tratamiento de los datos siguieron las recomendaciones de Chamale et al., (2012) con la ayuda del sosoftware Isoplot V4.15 (Ludwig, 2012).

Por otro lado, el equipo SGC analizó 5 muestras por el mismo método U-Pb LA-ICP-MS en circones concentrados en el laboratorio químico del Servicio Geológico Colombiano sede Medellín, utilizando separación hidrodinámica y magnética. Los circones se seleccionaron manualmente con lupa binocular en el Laboratorio de Petrografía de la sede Medellín.

De los montajes de granos de circón se adquirieron imágenes de catodoluminiscencia (CL) por medio de luminoscopios. Los análisis isotópicos de las muestras se llevaron a cabo en el Laboratorio de Geocronología del Servicio Geológico Colombiano, siguiendo los procedimientos descritos en Peña-Urueña et al., (2018). Estos se realizaron en un equipo de ablación Photon Machines con un láser Excimer de 193 nm, acoplado a un espectrómetro de masas tipo Element 2. Los isótopos utilizados para la integración manual fueron $238 \mathrm{U}, 206 \mathrm{~Pb}$ y $204 \mathrm{~Pb}$. Como patrones de referencia se usaron: Plešovice (Sláma et al., 2008), FG-1 (Coyner et al., 2004), Zircon 91500 (Wiedenbeck et al., 2004) y Mount Dromedary (Renne et al., 1998). Los puntos analizados en los circones fueron de 30 micrones de diámetro. La reducción de datos se realizó Iolite v2.5® en IGORPro6.3.6.4 ${ }^{\circledR}$ (Paton et al., 2010). La corrección por plomo común se realizó de acuerdo con el modelo de evolución según Stacey y Kramers (1975). Los resultados finales corresponden a la media de los datos obtenidos luego de aplicar una discriminación de datos a 2 desviaciones estándar. Los cálculos de las edades y los gráficos geocronológicos se hicieron con el programa Isoplot V4.15 (Ludwig, 2012).

\section{Geología Regional}

Las rocas agrupadas bajo la denominación "Batolito de Sabanalarga" se localizan en la zona de confluencia de 4 terrenos geológicos (Caribe, Arquía, Quebradagrande y Tahamí (Gómez et al., 2015)), y del sistema de fallas Cauca-Romeral (SFCR), sistema de fallas que se extiende a lo largo de $2000 \mathrm{~km}$ desde el norte de Antioquia hasta el sur en Ecuador (Figura 1A; Villagómez, 2010). A continuación, se describen las principales características de cada uno de estos elementos geológicos para determinar las posibles relaciones de los mismos con el Batolito de Sabanalarga.

El sistema de fallas Cauca-Romeral es un sistema complejo, pues está compuesto por múltiples estructuras con dirección predominante norte-sur. Este sistema es enmarcado al occidente por la falla Cauca-Oeste y al oriente por la falla San Jerónimo. A la altura del municipio de Liborina $\left(6^{\circ} 40^{\prime} \mathrm{N}\right)$ y en dirección norte, sus estructuras aparentan unirse en una sola, denominada Falla de Sabanalarga. Giraldo (2017) identificó que las estructuras componentes del sistema Cauca-Romeral en realidad no se unen y continúan al norte como al menos dos paralelas, separadas por cientos de metros. Estas últimas corresponden a las continuaciones al norte de Liborina de las fallas Cauca-Oeste y San Jerónimo. Al interior del sistema Cauca-Romeral se presentan múltiples bloques tectónicos como los terrenos Arquía y Quebradagrande, los cuales presentan orígenes e historias evolutivas aun en discusión. Cabe destacar que el sistema CaucaRomeral limita al occidente con el terreno Caribe y al oriente con el terreno Tahamí.

\subsection{TERRENO GARIBE}

En el terreno Caribe (Gómez et al., 2015) se encuentran agrupadas las rocas del Plateau Caribe (Kerr et al., 1997a; Cediel et al., 2003) las cuales fueron acrecionadas al noroccidente de la placa suramericana y al occidente del SFCR, constituyendo la base de la Cordillera Occidental de Colombia (Figura 1B). Están compuestas por rocas volcánicas básicas, de edades Jurásico- Cretácico (Rodríguez y Arango., 2013; Toussaint y Restrepo, 1978); y están intruidas por cuerpos de afinidad adakitica con edades $\mathrm{U}-\mathrm{Pb}$ que indican una edad máxima Turoniano- Aptiano (Rodríguez y Arango., 2013; Weber et al., 2015; Zapata-Villada et al., 2017). Sobrepuestas por unidades volcano- 
clásticas (Zapata-Villada et al., 2017; Buchs et al., 2018; Pardo-Trujillo et al., 2020) y sedimentarias con registros de amonites con edades bioestratigráficas Campaniano- Maastrichtiano (Castro y Feininger, 1965; Etayo et al., 1980; Geoestudios, 2005; Pardo-Trujillo et al., 2020) y basados en correlaciones composicionales, estas unidades volcánicas han sido correlacionadas al Sur con la Formación Volcánica (Barrero, 1979; Kerr et al., 1997a; Villagómez et al.,2010), con rocas del terreno Alao en Ecuador (Litherland et al., 1994), y al Norte con fragmentos del Caribe como Bonaire, Aruba e Hispañola (Wright and Wyld, 2011).

\subsection{TERRENO QUEBRADAGRANDE}

Constituido por el Complejo Quebradagrande (Botero, 1963; Maya y González, 1995), está compuesto por gabros, dioritas, flujos de basaltos $\mathrm{y}$ andesitas tan como se muestra en la figura $1 \mathrm{~b}$. El Complejo Quebradagrande presenta edades bioestratigráficas Albiano-Aptiano y edades $\mathrm{U}-\mathrm{Pb}$ entre 114-84 Ma (Maya y Gonzales, 1995; Villagómez et al., 2011; Cochrane et al., 2014; Zapata et al., 2018). Las rocas volcánicas del Complejo Quebradagrande han sido correlacionadas a rocas del Terreno Alao al norte en Ecuador (Cochrane et al., 2014) y asociadas a un ambiente de cuenca de retroarco con un magmatismo que se extiende entre ca. 114 Ma hasta 80 Ma (Villagómez, 2010, Spikings et al.,2015; Jaramillo et al., 2017).

\subsection{TERRENO ARQUÍA}

Definido como Grupo Arquía (Restrepo y Toussaint, 1975), esta unidad agrupa metagabros, anfibolitas granatíferas, esquistos anfibólicos, esquistos de cuarzo-micáceos, cuarcitas, eclogitas, esquistos de glaucofana-lawsonita y rocas ultramáficas serpentinizadas (Bustamante et al., 2011; Maya y González, 1995; Toussaint y Restrepo, 1978), limitados por la Falla Silvia-Pijao al Este y Cauca-Almaguer al Oeste, (Moreno-Sánchez y Pardo-Trujillo, 2003).

El terreno Arquía (Gómez et al., 2005) está conformado por fajas tectónicas extremadamente deformadas con relaciones estratigráficas y tectónicas complejas (Figura 1C). El ambiente de formación de las rocas del complejo Arquía ha sido asociado a un N-MORB (Villagómez et al., 2011; Rodríguez y Arango, 2013) con edades de enfriamiento ${ }^{40} \mathrm{Ar} /{ }^{39} \mathrm{Ar}$ y K/Ar de $127 \mathrm{Ma}, 110$ Ma y 117-107 Ma (Toussaint y Restrepo., 1978, Villagómez, 2010).

\subsection{TERRENO TAHAMÍ}

El Terreno Tahamí (Gómez et al., 2015) agrupa principalmente las rocas de los terrenos Tahamí (Restrepo y Toussaint,, 1988) y Panzenú (Restrepo et al., 2009). Está expuesto entre las Fallas San Jerónimo (al Oeste) y Otú- Pericos (al Este) (Figura 1B), y se compone por esquistos, anfibolitas y gneises de edades metamórficas Permo- Triásicas y Jurásicas (Gómez et al., 2007; Blanco- Quintero et al.,2014; Correa et al., 2017b, Rodríguez et al., 2016) de grado metamórfico medio a alto (Ordoñez-Carmona y Pimentel, 2002).

El terreno Tahamí fue intruido por cuerpos calco-alcalinos desde el Jurásico hasta el Cretácico (Bustamante et al., 2016; Rodríguez et al., 2016; Ibañez-Mejía et al., 2007), un ejemplo de estos es el Batolito Antioqueño (Ordoñez-Carmona, 2008; Leal-Mejía, 2011; Duque-Trujillo et al., 2019). Sobre este terreno reposan las rocas siliciclásticas de la Formación Abejorral con edades máximas de depositación de 120 Ma (Zapata, 2015, Zapata et al, 2018).

\section{Geología del área de estudio}

El "Batolito de Sabanalarga" (Álvarez y González, 1978; González, 2002; Rodríguez et al., 2012a), está compuesto por una serie de plutones que afloran al Este y al Oeste del sistema de fallas Cauca-Romeral, representado en esta latitud por la Falla Sabanalarga (Hall et al., 1972; Rodríguez et al., 2012a; Correa et al., 2018), Falla Romeral (Mejía y González, 1983) o Cauca-Almaguer (Nivia y Gómez, 2005), y representa un problema cronoestratigráfico para la sutura o límite de terrenos acrecionados a la margen continental (limites terreno Calima y Tahami; Restrepo y Toussaint., 1988 ó Arquía, Quebradagrande y Tahamí; Gómez et al., 2015). 
En este trabajo se considerará la Falla Sabanalarga como límite entre los plutones orientales y occidentales que componen el batolito de Sabanalarga definido por Hall et al.,(1972). La existencia como un único batolito implica la acreción de terrenos oceánicos y continentales en el Cretáceo antes de $100 \mathrm{Ma}$ (edades U-Pb de La Tonalita de Buriticá). Suprimiendo la existencia del gran Arco del caribe (White et al., 1999; Pindell et al., 2005), desarrollado sobre corteza Plateau antes de colisionar con la Margen Continental (White et al.,1999; Nivia, 2001; Vallejo et al., 2006).

El problema estratigráfico ha sido parcialmente resuelto con base en petrografía, relaciones de campo y nuevos datos de geocronología U-Pb (Nivia y Gómez, 2005; Weber et al., 2015; Giraldo, 2017; Zapata-Villada, 2017; Correa et al.,2018) considerando la unidad como al menos dos cuerpos plutónicos contemporáneos, denominados "Cuarzodiorita de Sabanalarga" y el "Gabro de Santa Fe" (Figura 1C).

\subsection{GUARZODIORITA DE SABANALARGA}

La Cuarzodiorita de Sabanalarga, incluida por varios autores (González et al., 1976; Álvarez y González, 1978; González, 2002; Rodríguez et al., 2012a) dentro del "Batolito de Sabanalarga" fue descrita inicialmente como Plutón de Sabanalarga (Hall et al.,1972; Álvarez et al., 1975; Mejía et al.,1983), y aflora como un cuerpo elongado de dirección norte-sur de aproximadamente 260 $\mathrm{Km}^{2}$ de composición tonalítica, cuyo cuerpo principal se encuentra el este y noreste de Sabanalarga (Figura 2). Sin embargo, después fue incluida por varios investigadores (González et al., 1976; Álvarez y González, 1978; González, 2002; Rodríguez et al., 2012a) dentro del "Batolito de Sabanalarga", cuerpo descrito como intrusivo a ambos lados de la Falla Sabanalarga alcanzando un área de 460 $\mathrm{km}^{2}$.

Entendiendo que la definición inicial del cuerpo fue al este de la Falla Sabanalarga, es decir, al este de la falla más occidental del sistema CaucaAlmaguer (Figura 2), y debido a las diferencias petrológicas (contenido de ferromagnesianos con radicales hidroxilos, e.g. anfíboles y biotita) (Nivia y Gómez, 2005) y geocronológicas (Weber et al.,
2015; Zapata-Villada et al., 2017; Giraldo, 2017), denominamos "Cuarzodiorita de Sabanalarga" siguiendo la propuesta de Nivia y Gómez, (2005) y Correa et al., (2018) al cuerpo intrusivo localizado al este de la Falla Sabanalarga.

De esta manera, cabe mencionar que la Cuarzodiorita de Sabanalarga está compuesta principalmente por cuarzodioritas-tonalitas (Figura 3A y 3B), intruye secuencias metamórficas pelíticas en facies esquisto verde compuestas por esquistos de cuarzo-moscovita-grafito, cuarzo-tre-

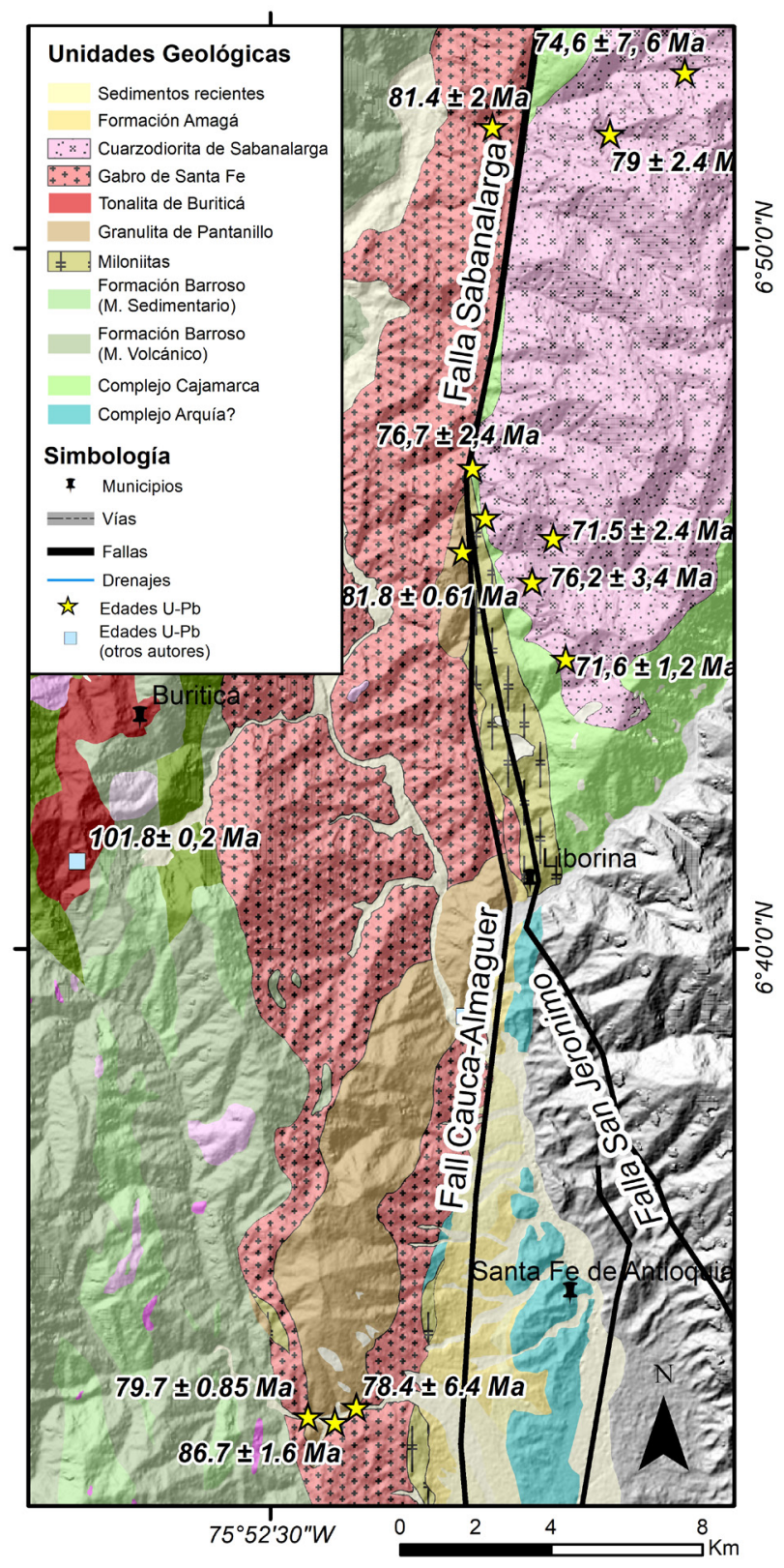

Figura 2 Mapa Geológico del área de estudio (En este trabajo). 
mollita-epidota-clorita asociadas al Complejo Cajamarca (Figura 3C), y al oeste se encuentra en contacto fallado con bloques de pillow lavas deformados asociadas al Complejo Quebradagrande (Correa et al., 2018). Para la Cuarzodiorita de

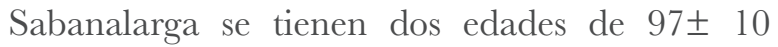
Ma K-Ar en biotita en (Gonzales et al., 1976) y

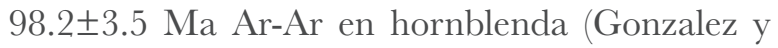
Londoño, 1998).

\subsection{GABRO DE SANTA FE}

Está compuesto por gabros, hornblenditas y en menor proporción, tonalitas y cuarzodioritas (Figura $3 \mathrm{E}$ y $3 \mathrm{~F}$ ) y corresponde al cuerpo localizado al oeste de la Falla Sabanalarga (Hall et al., 1972). El Gabro de Santa Fe intruye basaltos de la Formación Barroso al oeste (Figura 3G) y al este es limitado por la Falla Sabanalarga (Weber $e t$ al., 2015) y por milonitas asociadas (Correa et al., 2018); además, presenta abundantes xenolitos de la Granulita de Pantanillo (Figura 3G), interpretadas como asociados a raíces de arco magmático engrosado (Toro-Toro et al., 2020).

El Gabro de Santa Fe carece de ferromagnesianos y tiene radicales hidroxilos dentro de su estructura cristalina (Nivia y Gómez, 2005). Correa et al., 2018 nombran esta unidad como Tonalita de Santa Fe en base a análisis petrográficos; sin embargo, en este trabajo se observa que hay dos facies presentes: una máfica (gabroica) predominante y una intermedia (tonalitica).

El Gabro de Santa Fe presenta edades de 98土 9.1 Ma por el método Sm- Nd (Weber et al., 2011) y de $123.8 \pm 3.9 \mathrm{Ma}$ por K-Ar en hornblenda (Rodríguez et al., 2012a). Adicionalmente, se reportan edades U-Pb para cuerpos asociados como el Gabro de Altamira de 87.67 0.9 Ma (ZapataVillada et al., 2017) y la Tonalita de Buriticá de

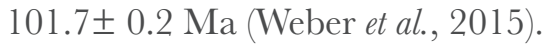

\section{Resultados}

\subsection{PETROGRAFÍA Y RELAGIONES DE GAMPO}

La Cuarzodiorita de Sabanalarga presenta una composición tonalítica, con variaciones a cuarzo- diorita y gabro.Intruye Esquistos de cuarzo-moscovita-grafito y Esquistos de cuarzo- tremollita-epidota del Complejo Cajamarca (terreno Tahamí), mostrados en abundantes xenolitos (Figura 3C); además, presenta enclaves de gabros (Figura 3G). Asimismo, la Cuazodiorita de Sabanalarga se observa en contacto fallado con bloques de basaltos que conservan estructuras pillow lavas, metasedimentos de bajo grado y rocas ultramaficas en la Qda. La sucia y Liborina.

Para esta unidad se analizaron 14 secciones delgadas, que presentan textura subidiomórfica, compuesta por cuarzo, plagioclasas, hornblenda y biotita. Como minerales accesorios se observan zircón y apatito; generalmente como inclusiones en biotita (Figura 3D). Como minerales de alteración, es común observar clorita y epidota.

El Gabro de Santa Fe está compuesto por dioritas hornblendicas, microdioritas, gabros $\mathrm{y}$ tonalitas hornblendicas (Figura 3E y 3F); y está rodeado por abundantes xenolitos de anfibolitas de la Granulita de Pantanillo (Rodríguez et al., 2012b) y basaltos de la Fm. Barroso (Figura 3G). Para el análisis de esta otra unidad se consideraron 40 secciones delgadas que caen entre el campo de gabros (facie máfica) y tonalitas (facie intermedia) (Figura 3E); asi cuatro muestras correspondientes a tonalitas para el Stock de Buriticá (Figura 3E). En general, las muestras revisadas presentan textura hipidiomórfica con presencia de plagioclasa, hornblenda, \pm piroxeno y cuarzo, como accesorio, y sausurita y calcita, como minerales de alteración (Figura 3H). La Tonalita de Buriticá está compuesta principalmente por cuarzo y plagioclasa (Giraldo, 2017).

La Cuarzodiorita de Sabanalarga y el Gabro de Santa Fe se encuentran separados por la Falla Sabanalarga o La Falla Cauca Oeste del sistema de fallas Cauca-Romeral. Al interior de este sistema se identificó una franja de mesomilonitas; mismas que están asociadas a secuencias vulcano-sedimentarias marinas. Algunos segmentos de estas fajas se encuentran cubiertos por segmentos de secuencias sedimentarias basculadas, compuestas por lutitas, areniscas y carbones, posiblemente asociadas a la Formación Amagá (Figura 2). 

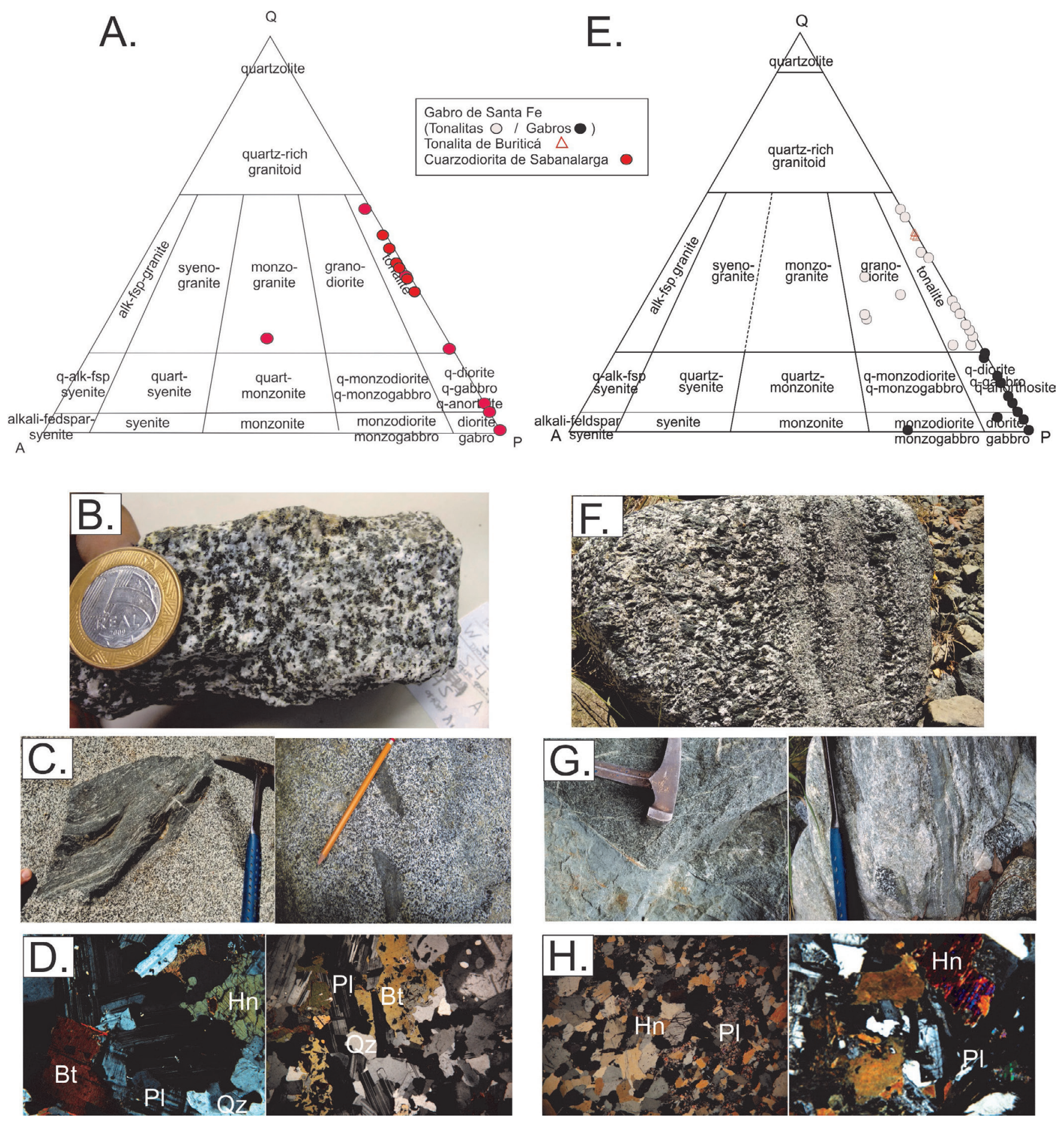

Figura 3 A. Clasificación petrográfica de la Cuarzodiorita de Sabanalarga. B. Muestra macro de una cuarzo-diorita. C. Izq: Xenolitos de esquistos de qz-msk-graf en Cuarzodiorita, Der: Gabarros de Gabros en Cuarzodioritas. D. Microfotografías correspondientes a la Cuarzodiorita de Sabanalarga. E. Clasificación petrográfica muestras Gabro de Santa Fe. F. Aspecto macroscópico del Gabro de Santa Fe. G. Izq: Contacto intrusivo del Gabro de Santa Fe en Basaltos de la Fm. Barroso, Der: Xenolitos de anfibolitas correspondientes a la Granulita de Pantanillo. H, Microfotografías del Gabro de Santa Fe. 


\subsection{GEOQUÍMICA}

De este trabajo y de otros anteriores (Weber et al, 2015; Geoestudios, 2005; ver Tabla 1), se analizaron elementos mayores y trazas de 12 muestras distribuidas entre monzogranitos, tonalitas, cuarzodioritas y gabros de la unidad Cuarzodiorita de Sabanalarga y dioritas, tonalitas y microgabros, correspondientes al Gabro de Santa Fe. Las muestras se encuentran relativamente frescas con valores "Loss on ignition" LOI $<2.8$ para la Cuarzodiorita de Sabanalarga y LOI $<1.8$ para el Gabro de Santa Fe.

Para las muestras de la Cuarzodiorita de Sabanalarga, el contenido de $\mathrm{SiO}_{2}$ varía entre 59.5 y $46.7 \%$; el contenido de $\mathrm{Al}_{2} \mathrm{O}_{3}$ varía entre 5.41- $16.9 \%$ y el de $\mathrm{MgO}$, entre 2.6-15.4 \%. De la misma manera, registra valores de $\mathrm{Sr}=78.6$ $504 \mathrm{ppm} \mathrm{Y}=12-25 \mathrm{ppm}$ y razones $\mathrm{Sr} / \mathrm{Y}=6.5-$
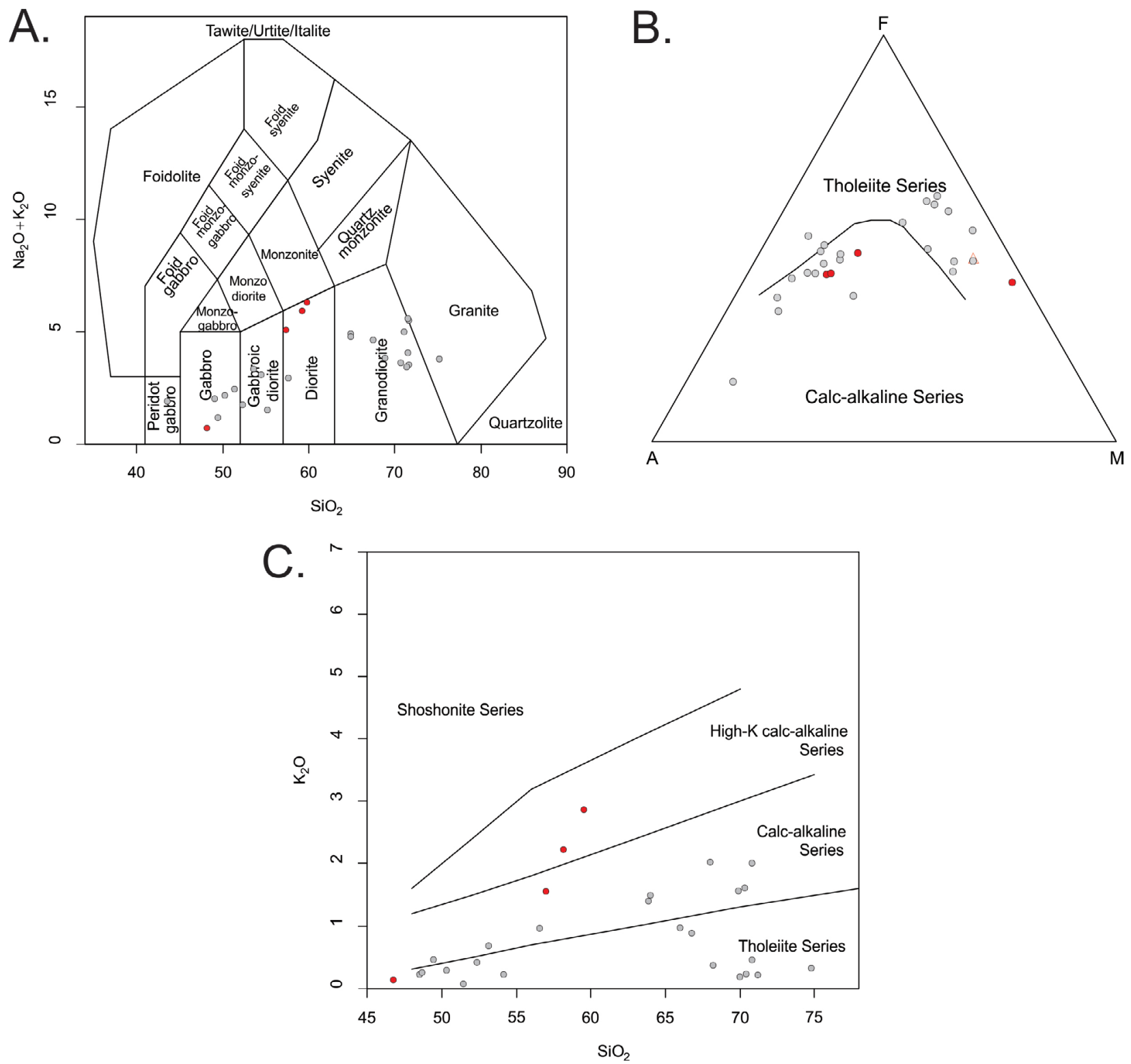

Figura 4 A Diagramas de discriminación tectónica B) TAS (Middlemost, 1985); b) AFM (Irvine \& Baragar, 1971); C) $\mathrm{SiO}_{2}$ vs $\mathrm{K}_{2} \mathrm{O}$ (Peccerillo y Taylor, 1976). 
Tabla 1. Elementos mayores y trazas para las muestras de la Cuarzodiorita de Sabanalarga y el Gabro de Santa Fe.

\begin{tabular}{|c|c|c|c|c|c|c|c|c|c|c|c|c|c|}
\hline \multirow[b]{2}{*}{ Muestra } & \multicolumn{4}{|c|}{ Cuarzodiorita de Sabanalarga } & \multirow[b]{2}{*}{ VR192R } & \multirow[b]{2}{*}{ AN1836 } & \multirow[b]{2}{*}{ TCR727A } & \multicolumn{6}{|c|}{ Gabro de Santa Fe } \\
\hline & $M G O-238$ & $A R O-247$ & $J P Z-174$ & LMC-353 & & & & GR5448 & DAN70 & VR422R & $J A 146$ & JGT116B & GR145R \\
\hline $\mathrm{SiO}_{2}$ & 59.5 & 58.17 & 56.96 & 46.75 & 43.11 & 48.49 & 48.67 & 49.45 & 51.46 & 52.35 & 53.12 & 56.57 & 63.82 \\
\hline $\mathrm{TiO}_{2}$ & 0.84 & 0.74 & 0.92 & 0.7 & 1.22 & 0.93 & 0.64 & 0.79 & 0.23 & 0.67 & 0.67 & 0.49 & 0.54 \\
\hline $\mathrm{Al}_{2} \mathrm{O}_{3}$ & 16.98 & 17.65 & 17.49 & 5.41 & 17.75 & 16.34 & 12.22 & 16.92 & 15.36 & 17.63 & 12.45 & 13.84 & 15.11 \\
\hline $\mathrm{Fe}_{2} \mathrm{O}_{3}$ & 6.86 & 6.56 & 7.97 & 11.55 & 14.85 & 12.87 & 13.2 & 12.43 & 9.86 & 9.88 & 9.4 & 8.64 & 6.37 \\
\hline$M g O$ & 2.6 & 2.58 & 3.29 & 15.41 & 7 & 6.38 & 9.76 & 5.67 & 9.31 & 4.52 & 9.01 & 5.94 & 2.35 \\
\hline $\mathrm{CaO}$ & 6.1 & 6.43 & 7.36 & 16.2 & 12.41 & 11.36 & 12.63 & 10.71 & 10.33 & 9.18 & 9.58 & 9.6 & 5.23 \\
\hline $\mathrm{Na}_{2} \mathrm{O}$ & 3.42 & 3.59 & 3.47 & 0.56 & 1.61 & 1.83 & 0.86 & 1.7 & 1.58 & 2.81 & 2.28 & 1.88 & 3.38 \\
\hline $\mathrm{K}_{2} \mathrm{O}$ & 2.86 & 2.23 & 1.55 & 0.14 & 0.29 & 0.2 & 0.23 & 0.46 & 0.07 & 0.39 & 0.66 & 0.94 & 1.38 \\
\hline $\mathrm{P}_{2} \mathrm{O}_{5}$ & 0.23 & 0.25 & 0.25 & 0.08 & 0.4 & 0.35 & 0.09 & 0.13 & 0.03 & 0.15 & 0.26 & 0.12 & 0.11 \\
\hline$M n O$ & 0.13 & 0.13 & 0.15 & 0.2 & 0.25 & 0.25 & 0.21 & 0.18 & 0.18 & 0.18 & 0.16 & 0.18 & 0.11 \\
\hline LOI & 0.45 & 1.55 & 0.57 & 2.84 & 0.9 & 0.89 & 1.4 & 1.52 & 1.39 & 2.2 & 1.1 & 1.83 & 1.5 \\
\hline Sum & 99.97 & 99.88 & 99.99 & 99.99 & 99.8 & 99.89 & 100 & 100 & 99.8 & 100 & 98.69 & 100 & 99.9 \\
\hline$L i$ & 33.13 & 15.81 & 27.36 & 11.75 & & & 1.13 & & & & & & \\
\hline $\mathrm{Be}$ & 2.55 & 2.34 & 1.68 & 0.44 & & & 0.31 & & & & & & \\
\hline$S c$ & 25.29 & 22.86 & 31.93 & 116.76 & 36 & 39 & 80.28 & 40 & 38 & 24 & 33 & 47 & 19 \\
\hline Co & 22.56 & 20.65 & 24.32 & 120.35 & 45.8 & 32 & 58.47 & & 49 & 29 & 39 & 29 & 15.5 \\
\hline $\mathrm{Ni}$ & 8.45 & 8.99 & 8.62 & 113.49 & 18 & 40 & 83.22 & 10 & 100 & 20 & 90 & 40 & 5 \\
\hline $\mathrm{Cu}$ & 29.33 & 12.45 & 12.29 & 280.79 & & 130 & 38.45 & & 30 & & 20 & 70 & \\
\hline$Z n$ & 94.9 & 95.52 & 103.66 & 69.2 & & 100 & 92.83 & & 90 & & 70 & 70 & \\
\hline Ga & 19.68 & 23.39 & 24.03 & 7.37 & 18.4 & 17 & 13.29 & 15 & 15 & 17.1 & 15 & 15 & 15 \\
\hline As & 3.34 & 1.67 & 1.2 & 2.22 & & & 0.44 & & & & & & \\
\hline$R \boldsymbol{B}$ & 116.47 & 57.08 & 42.67 & 2.03 & 5.6 & 4 & 2.31 & 9 & 2 & 8.4 & 16 & 13 & 22.6 \\
\hline$S r$ & 365.32 & 502 & 504.51 & 78.69 & 445.1 & 364 & 151.52 & 327 & 185 & 377.4 & 384 & 324 & 227.3 \\
\hline$Y$ & 25 & 20 & 21 & 12 & 19.8 & 10.4 & 7 & 8.9 & 5.6 & 15.9 & 13 & 11.9 & 20.6 \\
\hline Cs & 2.87 & 0.85 & 1.35 & 0.06 & 0.1 & 0.1 & & 0.05 & & 0.2 & 0.4 & 0.2 & 0.2 \\
\hline$B a$ & 656.75 & 866.9 & 803.04 & 46.16 & 96.5 & 133 & 76.5 & 167 & 50 & 169.7 & 375 & 332 & 922.3 \\
\hline La & 12.65 & 13.85 & 12.01 & 5.94 & 6.1 & 3.61 & 4.95 & 4.26 & 1.25 & 5.9 & 7.14 & 7.98 & 7.1 \\
\hline $\mathrm{Ce}$ & 23.29 & 24.49 & 21.29 & 10.63 & 17 & 8.72 & 8.56 & 9.28 & 2.72 & 14.1 & 15.2 & 16.5 & 16.1 \\
\hline$P r$ & 3.62 & 3.73 & 3.24 & 1.22 & 2.67 & 1.32 & 0.7 & 1.39 & 0.4 & 2.19 & 2.32 & 2.29 & 2.35 \\
\hline$N d$ & 17.39 & 15.21 & 15.13 & 5.99 & 13.3 & 6.14 & 3.82 & 6.47 & 1.92 & 10.5 & 10.3 & 8.86 & 10.9 \\
\hline$S m$ & 4.09 & 3.75 & 3.95 & 1.98 & 3.4 & 1.6 & 1.21 & 1.6 & 0.57 & 2.4 & 2.56 & 2.02 & 2.8 \\
\hline$E u$ & 1.36 & 1.44 & 1.53 & 0.68 & 1.28 & 0.773 & 0.52 & 0.55 & 0.336 & 0.89 & 0.922 & 0.78 & 0.87 \\
\hline$G d$ & 4.39 & 4.09 & 4.31 & 2.35 & 3.63 & 1.75 & 1.38 & 1.74 & 0.64 & 2.52 & 2.3 & 1.84 & 3.24 \\
\hline$T b$ & 0.76 & 0.61 & 0.69 & 0.42 & 0.6 & 0.31 & 0.25 & 0.27 & 0.14 & 0.42 & 0.4 & 0.33 & 0.56 \\
\hline Dy & 4.48 & 3.7 & 3.99 & 2.62 & 3.47 & 1.84 & 1.45 & 1.61 & 0.92 & 2.6 & 2.35 & 2 & 3.16 \\
\hline Ho & 0.96 & 0.76 & 0.83 & 0.53 & 0.65 & 0.36 & 0.28 & 0.32 & 0.19 & 0.52 & 0.44 & 0.41 & 0.7 \\
\hline$E r$ & 2.93 & 2.36 & 2.51 & 1.52 & 1.91 & 1.07 & 0.85 & 0.95 & 0.57 & 1.58 & 1.3 & 1.22 & 2.02 \\
\hline Tm & 0.43 & 0.34 & 0.35 & 0.2 & 0.3 & 0.157 & 0.12 & 0.14 & 0.087 & 0.27 & 0.194 & 0.184 & 0.36 \\
\hline$Y b$ & 2.81 & 2.33 & 2.29 & 1.23 & 1.88 & 1.04 & 0.73 & 0.92 & 0.6 & 1.63 & 1.21 & 1.24 & 1.93 \\
\hline Lu & 0.43 & 0.37 & 0.35 & 0.16 & 0.28 & 0.164 & 0.11 & 0.15 & 0.102 & 0.26 & 0.187 & 0.19 & 0.3 \\
\hline Th & 3.49 & 2.65 & 1.79 & 0.41 & 0.1 & 0.28 & 0.18 & 0.14 & 0.15 & 0.5 & 0.77 & 1.56 & 0.9 \\
\hline$U$ & 1.67 & 0.95 & 0.69 & 0.2 & & 0.08 & 0.07 & 0.17 & 0.04 & 0.1 & 0.23 & 0.33 & 0.5 \\
\hline$v$ & 185 & 163 & 217 & 343 & 410 & 309 & 351 & 415 & 149 & 252 & 245 & 301 & 133 \\
\hline$Z r$ & 150 & 107 & 100 & 33 & 20.4 & 17 & 20 & 28 & 13 & 37 & 28 & 25 & 87.5 \\
\hline $\mathrm{Nb}$ & 5 & 4 & 4 & 3 & 2.9 & 1.5 & & 3 & 0.7 & 2.6 & 1.7 & 1.3 & 3.2 \\
\hline$H f$ & & & & & 0.8 & 0.6 & & 1 & 0.4 & 1.3 & 1 & 1 & 3.1 \\
\hline$E u / E u^{*}$ & 0.99 & 1.13 & 1.14 & 0.97 & 1.12 & 1.42 & 1.24 & 1.01 & 1.71 & 1.11 & 1.17 & 1.24 & 0.89 \\
\hline$L a N / Y b N$ & 3 & 3.96 & 3.5 & 3.22 & 2.16 & 2.31 & 4.52 & 3.09 & 1.39 & 2.41 & 3.93 & 4.29 & 2.45 \\
\hline $\operatorname{LaN} / \mathrm{SmN}$ & 1.91 & 2.27 & 1.87 & 1.85 & 1.1 & 1.39 & 2.52 & 1.64 & 1.35 & 1.51 & 1.72 & 2.43 & 1.56 \\
\hline Sum_REE & 79.58 & 77.03 & 72.47 & 35.49 & 56.47 & 28.85 & 24.93 & 29.65 & 10.45 & 45.78 & 46.82 & 45.84 & 52.39 \\
\hline
\end{tabular}


Tabla 1. (Continuación) Elementos mayores y trazas para las muestras de la Cuarzodiorita de Sabanalarga y el Gabro de Santa Fe.

\begin{tabular}{|c|c|c|c|c|c|c|c|c|c|c|c|c|c|c|c|}
\hline & \multicolumn{15}{|c|}{ Gabro de Santa Fe } \\
\hline Muestra & $\overline{G R 146 R}$ & TCR715 & TCR732 & $\overline{M R 152 R}$ & $J A 74$ & $\overline{T C R 437}$ & JPZ159A & VR301R & AN18344 & AN18342 & VR290R & $\begin{array}{l}J G T- \\
118 A\end{array}$ & $\begin{array}{l}L M C- \\
385 B \\
\end{array}$ & $\begin{array}{l}\text { TCR- } \\
812\end{array}$ & $\begin{array}{l}\text { TCR- } \\
815\end{array}$ \\
\hline $\mathrm{SiO}_{2}$ & 63.99 & 65.98 & 66.76 & 68.03 & 68.19 & 69.91 & 70 & 70.32 & 70.44 & 70.81 & 70.82 & 71.21 & 74.79 & 50.33 & 54.14 \\
\hline $\mathrm{TiO}_{2}$ & 0.54 & 0.32 & 0.53 & 0.3 & 0.42 & 0.36 & 0.31 & 0.39 & 0.33 & 0.34 & 0.35 & 0.32 & 0.23 & 0.63 & 0.38 \\
\hline $\mathrm{Al}_{2} \mathrm{O}_{3}$ & 15.01 & 15.04 & 15.63 & 15.67 & 15.13 & 14.24 & 14.79 & 13.97 & 13.9 & 13.64 & 13.8 & 14.06 & 14.5 & 16.81 & 14.73 \\
\hline $\mathrm{Fe}_{2} \mathrm{O}_{3}$ & 6.57 & 4.14 & 4.66 & 3.58 & 4.4 & 3.29 & 4.82 & 4.32 & 4.58 & 3.95 & 3.84 & 4.43 & 0.78 & 9.1 & 11.16 \\
\hline $\mathrm{MgO}$ & 2.31 & 2.72 & 1.5 & 1.37 & 1.39 & 1.07 & 0.73 & 1.01 & 1.13 & 1.12 & 0.94 & 1.14 & 0.51 & 8.05 & 6.37 \\
\hline $\mathrm{CaO}$ & 5.41 & 5.59 & 5.14 & 3.88 & 5.56 & 3.24 & 4.76 & 3.86 & 4.85 & 5.09 & 3.65 & 4.64 & 4.91 & 10.36 & 9.73 \\
\hline $\mathrm{Na}_{2} \mathrm{O}$ & 3.25 & 3.14 & 3.66 & & 3.37 & 3.76 & 3.36 & 3.29 & 3.13 & 3.53 & 3.48 & 3.25 & 3.39 & 2.14 & 1.23 \\
\hline $\mathrm{K}_{2} \mathrm{O}$ & 1.47 & 0.95 & 0.86 & 2 & 0.35 & 1.54 & 0.16 & 1.59 & 0.21 & 0.43 & 1.99 & 0.19 & 0.3 & 0.28 & 0.2 \\
\hline$P_{2} O_{5}$ & 0.12 & 0.1 & 0.15 & 0.19 & 0.16 & 0.11 & 0.08 & 0.12 & 0.07 & 0.08 & 0.11 & 0.13 & 0.08 & 0.177 & 0.06 \\
\hline $\mathrm{MnO}$ & 0.1 & 0.07 & 0.09 & 0.12 & 0.08 & 0.1 & 0.07 & 0.07 & 0.06 & 0.07 & 0.08 & 0.06 & 0.02 & 0.172 & 0.15805 \\
\hline LOI & 1.1 & 1.8 & 1.02 & 1 & 0.75 & 2.3 & 1.01 & 0.9 & 0.93 & 1.28 & 0.8 & 0.95 & 0.56 & 1.84 & 1.74 \\
\hline Sum & 99.9 & 99.9 & 100 & 96.1 & 99.81 & 99.9 & 100.1 & 99.8 & 99.65 & 100.3 & 99.9 & 100.4 & 100.1 & 99.95 & 99.97 \\
\hline$L i$ & & 9.51 & 1.63 & & & 2.63 & 3.21 & & & & & & 1.52 & 2.608 & 1.71447 \\
\hline$B e$ & & 1.62 & 1.34 & & & 1.34 & 0.72 & & & & & & 1.86 & 0.517 & 0.22657 \\
\hline$S c$ & 19 & 22.97 & 18.74 & 5 & 13 & 7.74 & 16.49 & 11 & 16 & 16 & 10 & 15 & 6.76 & 30.620 & 35.0867 \\
\hline Co & 15.3 & 22.3 & 17.88 & 5.6 & 9 & 15.59 & 17.12 & 6.6 & 8 & 7 & 8.4 & 9 & 18.02 & 33.698 & 43.7997 \\
\hline$N i$ & 66 & 20.36 & 5.43 & 5 & & 8.61 & 3.94 & 6 & & & 5 & & 4.02 & 89.5913 & 58.5825 \\
\hline $\mathrm{Cu}$ & & 40.96 & 6.91 & & 10 & 8.15 & 16.6 & & 10 & 60 & & 30 & 3.18 & 9.717 & 44.0194 \\
\hline$Z n$ & & 51.76 & 43.64 & & 40 & 52.44 & 46.32 & & & 50 & & & 10.81 & 61.965 & 67.004 \\
\hline$G a$ & 14.4 & 17.11 & 15.59 & 14.1 & 16 & 18.88 & 15.93 & 12.4 & 13 & 12 & 13.1 & 14 & 12.55 & 13.082 & 12.197 \\
\hline As & & 0.87 & 0.82 & & & 0.82 & 0.42 & & & & & & 0.88 & & \\
\hline$R b$ & 18.9 & 15.8 & 10.89 & 42 & 6 & 51.4 & 3.52 & 16.9 & 5 & 6 & 37.5 & 4 & 3.66 & 4.993 & 2.877 \\
\hline$S r$ & 268.9 & 732.38 & 352.66 & 523.4 & 354 & 282.45 & 191.5 & 221.3 & 136 & 145 & 203.2 & 137 & 362.91 & 369.347 & 145.726 \\
\hline$Y$ & 20.3 & 6 & 15 & 12.8 & 9.9 & 15.65 & 4 & 20.9 & 17.6 & 16.6 & 20.2 & 15 & 14 & 13 & 36 \\
\hline Cs & 0.2 & 0.4 & 0.06 & 0.7 & 0.1 & 0.27 & 0.12 & & & & 0.4 & & & 0.087 & \\
\hline$B a$ & 1011 & 1360.02 & 754.56 & 1861.1 & 198 & 441.96 & 137.32 & 1644.3 & 137 & 174 & 1220.1 & 147 & 355.89 & 323.897 & 118.815 \\
\hline$L a$ & 6.6 & 8.15 & 10.66 & 20.9 & 6.31 & 10.63 & 7.14 & 9 & 6.06 & 5.89 & 8 & 6.02 & 9.81 & 11.070 & 4.965 \\
\hline $\mathrm{Ce}$ & 16.6 & 13.7 & 19.35 & 40.3 & 12.4 & 20.45 & 9.7 & 20.8 & 12.8 & 12.2 & 18.6 & 12.4 & 16.27 & 20.228 & 8.561 \\
\hline $\operatorname{Pr}$ & 2.41 & 1.54 & 2.65 & 4.49 & 1.71 & 2.73 & 0.82 & 2.88 & 1.65 & 1.56 & 2.66 & 1.62 & 2.5 & 2.793 & 0.494 \\
\hline$N d$ & 10.4 & 6.62 & 11.93 & 16.9 & 6.76 & 11.8 & 3.61 & 12.6 & 6.84 & 6.6 & 11 & 6.74 & 10.68 & 12.340 & 2.475 \\
\hline$S m$ & 2.6 & 1.57 & 2.86 & 2.8 & 1.52 & 2.39 & 0.81 & 3 & 1.76 & 1.7 & 2.8 & 1.78 & 2.35 & 2.844 & 0.725 \\
\hline$E u$ & 0.75 & 0.97 & 1.14 & 0.75 & 0.637 & 1.1 & 0.65 & 0.79 & 0.609 & 0.555 & 0.81 & 0.593 & 0.78 & 1.150 & 0.369 \\
\hline$G d$ & 3.17 & 1.43 & 2.9 & 2.09 & 1.36 & 2.32 & 0.95 & 3.43 & 2.03 & 2.02 & 3.39 & 1.92 & 2.21 & 2.831 & 0.781 \\
\hline$T b$ & 0.55 & 0.2 & 0.46 & 0.35 & 0.25 & 0.4 & 0.13 & 0.62 & 0.4 & 0.4 & 0.57 & 0.38 & 0.36 & 0.444 & 0.145 \\
\hline Dy & 3.31 & 1.04 & 2.63 & 2.07 & 1.58 & 2.21 & 0.78 & 3.55 & 2.65 & 2.6 & 3.44 & 2.58 & 1.97 & 2.530 & 0.949 \\
\hline Ho & 0.64 & 0.2 & 0.54 & 0.42 & 0.32 & 0.47 & 0.16 & 0.72 & 0.56 & 0.55 & 0.71 & 0.55 & 0.43 & 0.535 & 0.202 \\
\hline Er & 2.11 & 0.55 & 1.58 & 1.33 & 0.94 & 1.42 & 0.48 & 2.07 & 1.74 & 1.72 & 2.21 & 1.65 & 1.35 & 1.586 & 0.609 \\
\hline$T m$ & 0.31 & 0.07 & 0.23 & 0.23 & 0.142 & 0.21 & 0.06 & 0.35 & 0.268 & 0.268 & 0.35 & 0.26 & 0.21 & 0.224 & 0.091 \\
\hline$Y b$ & 2.02 & 0.47 & 1.48 & 1.36 & 0.97 & 1.39 & 0.45 & 2.32 & 1.85 & 1.78 & 2.31 & 1.75 & 1.45 & 1.483 & 0.592 \\
\hline Lu & 0.32 & 0.06 & 0.23 & 0.26 & 0.153 & 0.22 & 0.07 & 0.35 & 0.287 & 0.282 & 0.37 & 0.281 & 0.24 & 0.231 & 0.102 \\
\hline Th & 1 & 1.41 & 1.73 & 5.2 & 1.73 & 2.17 & 0.22 & 1.6 & 0.99 & 0.94 & 1.8 & 0.94 & 6.86 & 1.609 & 0.169 \\
\hline$U$ & 0.5 & 0.68 & 0.36 & 0.8 & 0.37 & 0.3 & 0.15 & 0.7 & 0.26 & 0.25 & 0.6 & 0.23 & 0.86 & 0.897 & 0.492 \\
\hline$V$ & 131 & 96 & 103 & 56 & 89 & 40.7 & 35 & 61 & 55 & 59 & 58 & 59 & 28 & 248 & 252 \\
\hline$Z r$ & 84.7 & 54 & 81 & 79.5 & 96 & 94.2 & 54 & 108.9 & 80 & 76 & 111.4 & 81 & 57 & 38 & 15 \\
\hline$N b$ & 3.3 & 2 & 4 & 3.7 & 2.9 & 5.9 & 2 & 4.3 & 5.1 & 4.7 & 4.4 & 4.6 & 4 & 2 & \\
\hline$H f$ & 2.8 & & & 2.5 & 2.2 & & & 3.5 & 2.1 & 2 & 3.6 & 2 & & & \\
\hline$E u / E u^{*}$ & 0.8 & 1.99 & 1.22 & 0.95 & 1.36 & 1.44 & 2.28 & 0.76 & 0.99 & 0.92 & 0.81 & 0.99 & 1.05 & 1.25 & 1.51 \\
\hline$L a N / Y b N$ & 2.18 & 11.56 & 4.8 & 10.25 & 4.34 & 5.1 & 10.58 & 2.59 & 2.18 & 2.21 & 2.31 & 2.29 & 4.51 & 4.97 & 5.59 \\
\hline $\operatorname{LaN} / \mathrm{Sm} N$ & 1.56 & 3.19 & 2.29 & 4.59 & 2.55 & 2.74 & 5.42 & 1.85 & 2.12 & 2.13 & 1.76 & 2.08 & 2.57 & 2.39 & 4.21 \\
\hline Sum_REE & 51.79 & 36.57 & 58.64 & 94.25 & 35.05 & 57.74 & 25.81 & 62.48 & 39.5 & 38.12 & 57.22 & 38.52 & 50.61 & 60.3 & 21.07 \\
\hline
\end{tabular}


25.1 y La/Yb=4.4-5.9. En el diagrama TAS (Middlemost, 1994) las muestras caen en el campo de los gabros y dioritas (Figura 4A), en el diagrama AFM (Irvine and Baragar, 1971) las muestras caen en el campo de las series calco-alcalinas y una muestra (LMC-353) corresponde a las series toleíticas (Figura 4B). En el diagrama de $\mathrm{SiO}_{2}$ vs $\mathrm{K}_{2} \mathrm{O}$ (Peccerillo y Taylor, 1976) las muestras varían de las series toleíticas, series calco- alcalinas hasta las series altas en $\mathrm{K}_{2} \mathrm{O}$ (Figura 4C).

Para las muestras del Gabro de Santa Fe, el contenido de $\mathrm{SiO}_{2}$ varía entre 74.7-48.6 \%; el de $\mathrm{Al}_{2} \mathrm{O}_{3}$, varía entre 0.78 a $13.2 \%$; el de $\mathrm{MgO}$, varía entre $0.5-9.76 \%, \mathrm{Na}_{2} \mathrm{O}=0.86-3.76 \%$; y el de $\mathrm{K}_{2} \mathrm{O}$, varía entre 0.2 hasta $1.4 \%$; presentando valores de $\mathrm{Sr}=151-732 \mathrm{ppm}, \mathrm{Y}=7-20.9 \mathrm{ppm}$ y razones $\mathrm{Sr} / \mathrm{Y}=9-122$ y $\mathrm{La} / \mathrm{Yb}=2.08-7.6$ afines con algunas características adakíticas (Kay and Kay, 2002). En el diagrama TAS (Middlemost, 1994), las muestras caen en el campo de los gabros, gabro-dioritas, dioritas y granitos (Figura 4A); en el diagrama AFM (Irvine y Baragar, 1971), las muestras se distribuyen en dos grupos bien definidos en la figura $4 \mathrm{~b}$ entre muestras de las series calco-alcalinas (muestras intermedias) y las series toleíticas (muestras máficas). Por último, en el diagrama de $\mathrm{SiO}_{2}$ vs $\mathrm{K}_{2} \mathrm{O}$ (Peccerillo y Taylor, 1976), las muestras se distribuyen igualmente entre dos

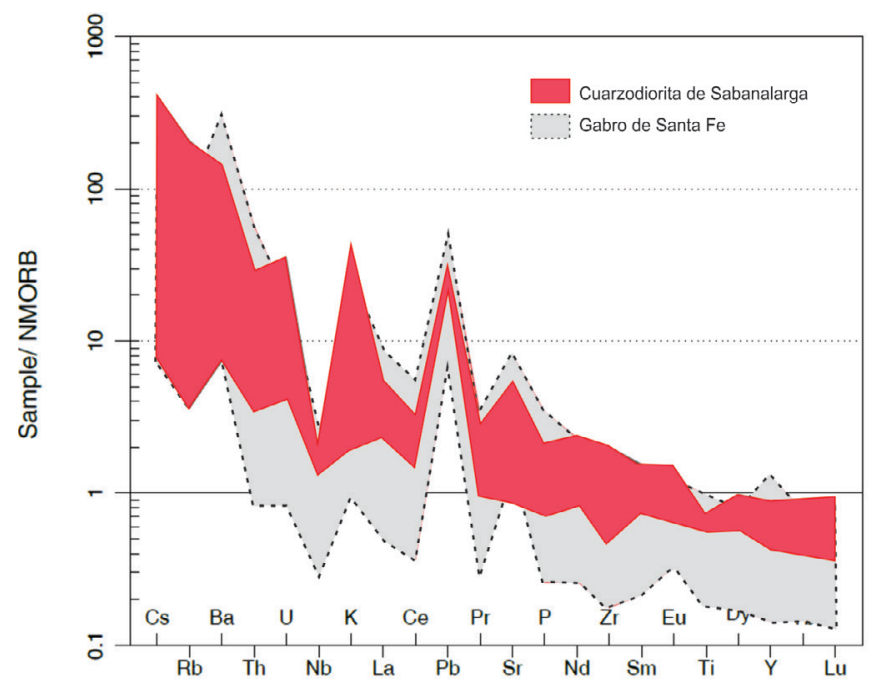

grupos, entre las series toleíticas y las series calco-alcalinas (Figura 4C).

Las muestras de la Cuarzodiorita de Sabanalarga normalizadas al N-MORB (Sun y McDonough, 1989), presentan enriquecimiento en "Large Ion Lithophile elements" (LILE). En comparación con los "High Field Strength elements" HFSE y las tierras raras (REEs), con anomalías negativas de Ta, $\mathrm{Nb}-\mathrm{Ti}$ y enriquecimientos en Cs, Ba y K (Figura $5 \mathrm{~A})$, características de magmas formados en una zona de subducción. Normalizadas al Condrito (Nakamura, 1974), las muestras presentan enriquecimiento en tierras raras livianas respecto a las tierras raras pesadas, con razones $(\mathrm{La} / \mathrm{Yb})_{\mathrm{N}}=$ 3.0-3.96 y $(\mathrm{La} / \mathrm{Sm})_{\mathrm{N}}=2.85-2.27$ (Figura 5B).

Las muestras del Gabro de Santa Fe normalizadas al N-MORB (Sun y McDonough, 1989), presentan enriquecimiento en LILE respecto a HFSE y las REEs, con anomalías negativas de $\mathrm{Nb}-\mathrm{Ti}$, y anomalías positivas de Ba, Cs y K (Figura 5A), afines a magmas formados en ambientes de subducción. Normalizados al Condrito (Nakamura, 1974), las muestras presentan enriquecimiento en HREE, respecto a LREEs, con valores $(\mathrm{La} / \mathrm{Yb})_{\mathrm{N}}=$ 2.16-11.5, y $(\mathrm{La} / \mathrm{Sm})_{\mathrm{N}}=1.35-5.42$ (Figura 5B).

En el diagrama de clasificación $\mathrm{Nb} / \mathrm{Yb}-\mathrm{Th} / \mathrm{Yb}$ (Pearce, 2008) se observa que tanto las muestras de la Cuarzodiorita de Sabanalarga y el Gabro de

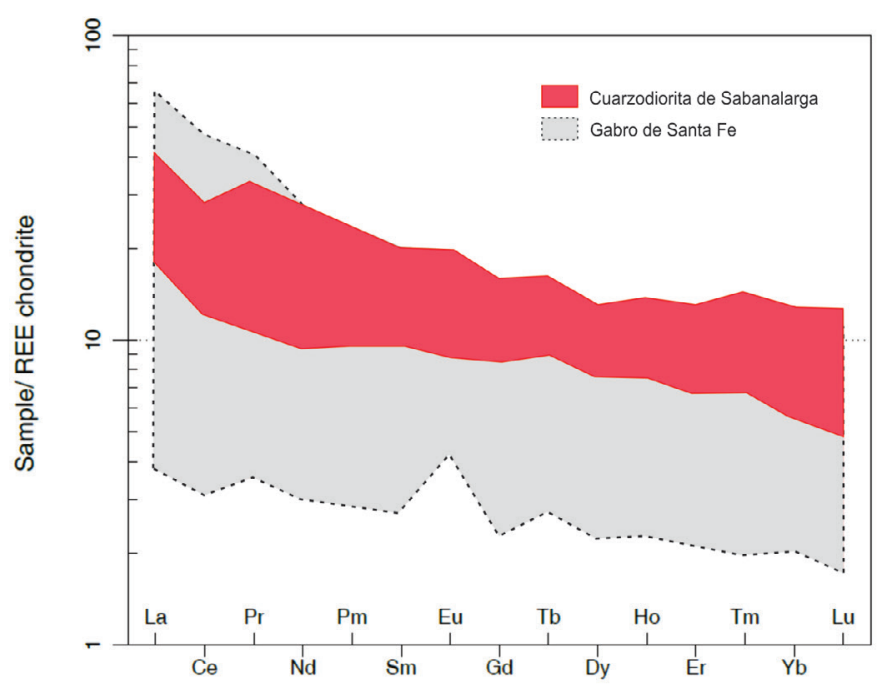


Santa Fe presentan enriquecimiento en $\mathrm{Th}$ y $\mathrm{Nb}$ (Figura 6A), característico de magmas sometidos a proceso de interacción con corteza en ambientes de subducción (Pearce, 2008). En el diagrama de Condie y Kroner (2013), se observa que las muestras correspondientes a la Cuarzodiorita de Sabanalarga presentan altos valores $(\mathrm{La} / \mathrm{Yb})_{\mathrm{N}}$ vs Sr/Y, correspondientes a arcos continentales; mientras que las muestras del Gabro de Santa Fe se dispersan entre arcos oceánicos y arcos continentales (Figura 6B).

Además, razones $(\mathrm{La} / \mathrm{Yb})_{\mathrm{N}}=3-3.96$ y $\mathrm{Sr} / \mathrm{Y}=$ 14-25 y un espesor cortical aproximado de 23-29.7 Km (Profeta et al., 2015) fueron calculados para la Cuarzodiorita de Sabanalarga. Igualmente razones $(\mathrm{La} / \mathrm{Yb})_{\mathrm{N}}=2.18-11.56$ y $\mathrm{Sr} / \mathrm{Y}=11-122$ y un espesor cortical de ca. 17-52 Km (Profeta et al., 2015) fueron calculados para el Gabro de Santa Fe.

\subsection{GEOGRONOLOGÍA}

Los análisis geocronológicos fueron realizados siguiendo metodologías distintas por los grupos SGC y UERJ y su distribución espacial se puede observar en la figura 2.

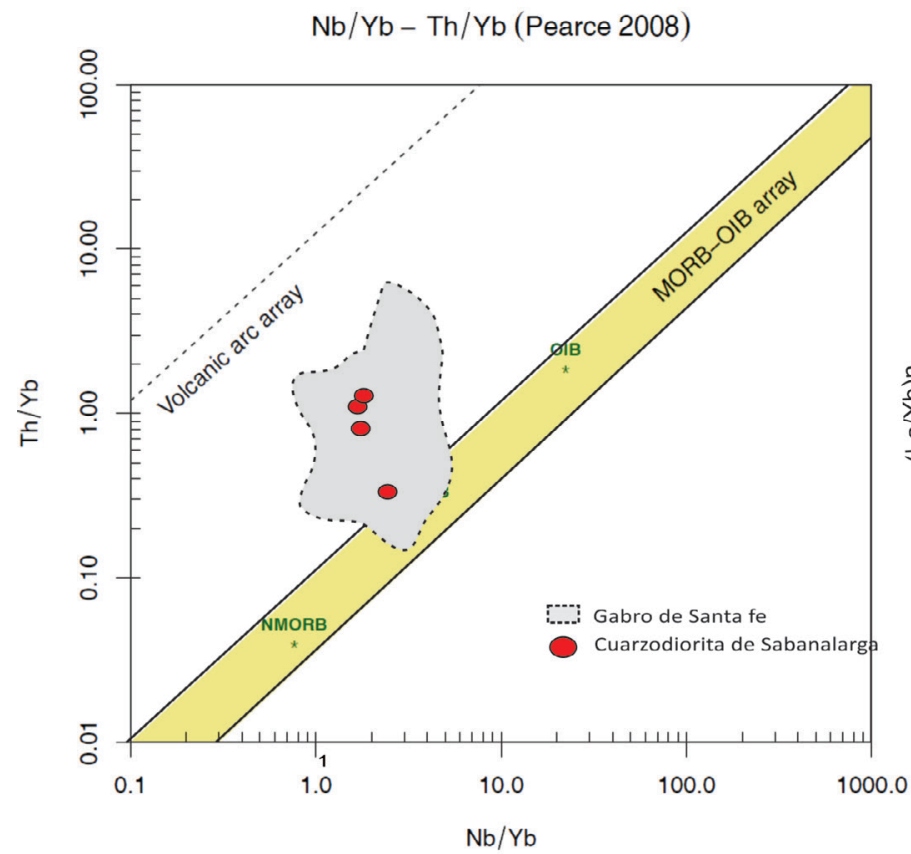

En el SGC fueron analizadas 5 muestras; 2 de la Guarzodiorita de Sabanalarga (muestras JPZ-178 y MGO-238), y 3 del Gabro de Santa Fe (muestras JPZ-121,JPZ-159A, TCR-815). El grupo de trabajo UERJ analizó 10 muestras; de las cuales, 4 corresponden a la Cuarzodiorita de Sabanalarga (WSS, W67TR, W65MT), 4 al Gabro de Santa Fe (WSF, W68SC, W64SA y WTrCa), 1 al Stock de Buriticá (WBR) (Anexo 1).

\subsubsection{CUARZODIORITA DE SABANALARGA}

En la muestra JPZ-178 (granodiorita) se analizaron 45 circones, subhedrales a euhedrales, prismáticos alargados e incoloros, con tamaños entre 70 y 100 $\mu \mathrm{m}$. A pesar de la catodoluminiscencia (CL) no ser de buena resolución se observan texturas de zonación oscilatoria concéntrica, texturas de reabsorción magmáticas (Vavra et al., 1999) y valores Th/U $=0.57$ 0.28 típicos de circones magmáticos (Rubatto, 2002). La edad media ponderada de cristalización de la muestra se calculó a partir de la relación ${ }^{206} \mathrm{~Pb} /{ }^{238} \mathrm{U}$ $71.6 \pm 1.2 \mathrm{Ma}(\mathrm{MSWD}=1.7, \mathrm{n}=26$; Figura 7).

En la muestra MGO-238 (granodiorita), se analizaron 53 circones subhedrales a euhedrales, pris-

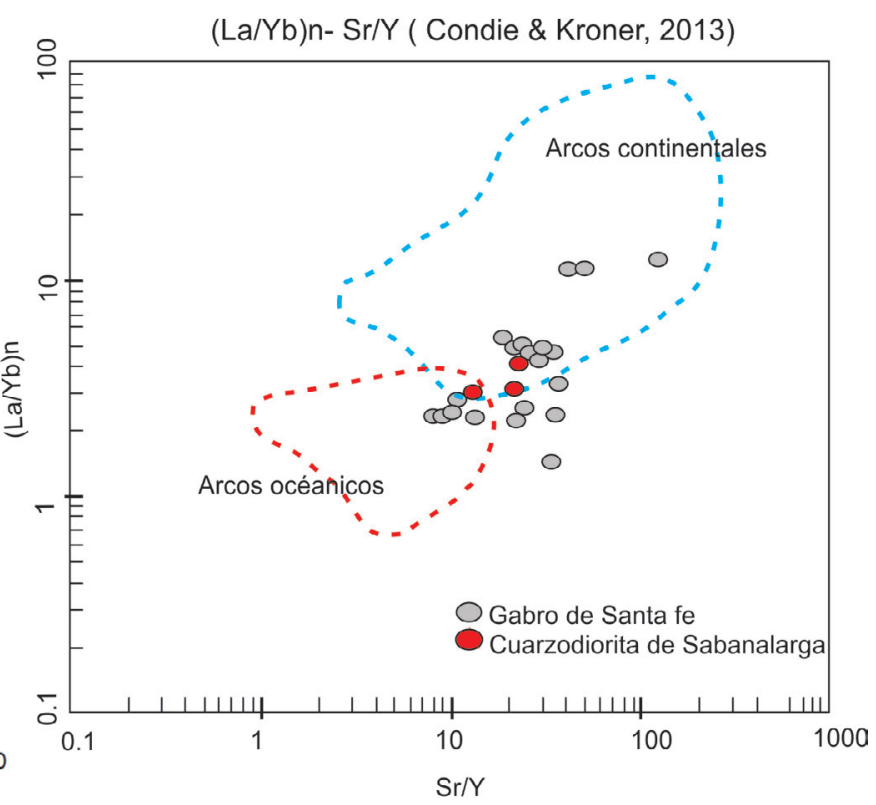

Figura 6 A. Diagrama de discriminación tectónica Nb/Yb vs Th/Yb (Pearce, 2008). B. Diagrama de discriminación (La/Yb)n vs Sr/Y (Condie \& Kroner, 2013). 
máticos alargados e incoloros, con tamaños entre 100 y $120 \mu \mathrm{m}$. En imágenes de CL se observan algunas texturas de zonación oscilatoria concéntrica y texturas de reabsorción típicas de circones magmáticos (Vavra et al., 1999). En el diagrama concordia Wetherill, se presentan dos poblaciones de datos: el primero alrededor de 75-80 Ma y el segundo entre 95-120 Ma (Figura 7). La edad media ponderada de cristalización se calculó ${ }^{206} \mathrm{~Pb} /{ }^{238} \mathrm{U}$ de $71.5 \pm 2.4 \mathrm{Ma}$ (MSWD de 2,4, $\mathrm{n}=8$ ). En el diagrama Concordia (Figura 7), se observan edades heredadas del segundo grupo de datos de: $96,38 \pm 4,4,103,68 \pm 5,2,108,53 \pm 5,76$ y $112,30 \pm 7,73 \mathrm{Ma}$, correspondientes posiblemente a edades heredadas de la roca caja. Para los circones analizados entre 75-80 Ma, se obtuvieron relaciones $\mathrm{Th} / \mathrm{U}$, entre 0.29 y 0.5 asociados a circones magmáticos (Rubatto, 2002). Mientras que para las herencias (> $90 \mathrm{Ma}$ ), se obtuvieron valores $\mathrm{Th} / \mathrm{U}$ entre 0,07 y 0,043 afines con valores presentes en rocas metamórficas (Rubatto, 2002).

Las 4 muestras siguientes (WSS, W67TR, W65MT, W66HD), presentan circones ígneos euhedrales muy homogéneos y sin núcleos heredados, con tamaños entre 200 y 500 Micras (Figura 7). Los diagramas de concordia presentan dos poblaciones, una de ellas presenta elipses alargadas horizontalmente, asociados a errores mayores en la proporción ${ }^{207} \mathrm{~Pb} /{ }^{235} \mathrm{U}$. La segunda población presenta elipses alargados diagonalmente con errores mayores en la proporción ${ }^{206} \mathrm{~Pb} /{ }^{238} \mathrm{U}$. Los resultados de estas se describen a continuación:

En la muestra WSS (tonalita) se analizaron 18 granos de circón con tamaños entre 250 y $500 \mu \mathrm{m}$ y valores $\mathrm{Th} / \mathrm{U}=0.79-0.38$, típicos de circones magmáticos (Rubatto, 2002), quince granos y permitieron calcular una edad de $76.2 \pm 3.4 \mathrm{Ma}$ (Figura 7).

Para la muestra W67TR (tonalita), se analizaron 32 granos de circón, con tamaños que varían desde 200 hasta $400 \mu \mathrm{m}$, y valores Th/U=0.690.36 típicos de circones magmáticos (Rubatto, 2002). No obstante, debido a altas concentraciones de 206 Pb, solo se consideraron los datos de 12 granos, los cuales permitieron calcular una edad de $74.6 \pm 7.6 \mathrm{Ma}$ (Figura 7).
En la muestra W65MT (cuarzodiorita), se analizaron dieciocho granos de circón con tamaños entre 200 y $300 \mu \mathrm{m}$ y valores $\mathrm{Th} / \mathrm{U}=0.50-0.25$ típicos de circones magmáticos (Rubatto, 2002). Esta muestra no presentó núcleos heredados o zircones metamórficos (Figura 7), por lo que permitió calcular una edad de 85, $4 \pm 2.4 \mathrm{Ma}$. Incluso discordante, la edad presenta un error pequeño.

En la muestra W66HD (tonalita) se analizaron dieciocho granos de zircón, con tamaños entre 200 y $400 \mu \mathrm{m}$ y valores $\mathrm{Th} / \mathrm{U}=0.64-0.29$, típicos de circones magmáticos (Rubatto, 2002); mismos que permitieron calcular una edad de $76.7 \pm 2.4 \mathrm{Ma}$ (Figura 7). Los granos en esta muestra se presentan en dos poblaciones con errores y edades similares.

\subsubsection{GABRO DE SANTA FE}

En la muestra JPZ-121 (tonalita hornblendica) fueron analizados 54 circones subhedrales a euhedrales, prismáticos cortos e incoloros, con tamaños entre 75 y $150 \mu \mathrm{m}$ (Figura 8) y razones $\mathrm{Th} / \mathrm{U}=0.25-1.19$, típicos de circones ígneos (Rubatto, 2002). El rango de dataciones obtenido varía entre 76 hasta $96 \mathrm{Ma}$ en el diagrama Tera Wasserburg (Figura 8). Su edad fue calculada a partir de la relación ${ }^{206} \mathrm{~Pb} /{ }^{238} \mathrm{U}$ en $79.71 \pm 0.85$ $\mathrm{Ma}(\mathrm{MSWD}=1.09, \mathrm{n}=18)$ (Figura 8).

Para la muestra JPZ-159A (tonalita), se analizaron 25 circones subhedrales a euhedrales, prismáticos e incoloros, y algunos rotos con tamaños entre 50 y $150 \mu \mathrm{m}$ (Figura 8). En las imágenes de CL se observa zonación oscilatoria. Las edades varían entre 86.9 a $88.3 \mathrm{Ma}$ y son concordantes en el diagrama Tera Wasserburg (Figura 8). La edad media ponderada fue calculada ${ }^{206} \mathrm{~Pb} /{ }^{238} \mathrm{U}$ de $86.7 \pm 1.6 \mathrm{Ma}(\mathrm{MSWD}=2.6, \mathrm{n}=23)$, con valores $\mathrm{U} / \mathrm{Th}=0.9-0.78$; valores típicos de circones ígneos (Rubatto, 2002).

Para la muestra TCR-815 (microgabro), se analizaron 166 circones, subhedrales a anhedrales, rotos o como prismas cortos con tamaños entre 50 y $100 \mu \mathrm{m}$ (Figura 8). En imágenes de CL los circones presentan zonación oscilatoria. El rango de la muestra varía de 76 a 89 Ma y son concordantes en el diagrama Tera Wasserburg (Figura 8). Finalmente, su edad fue calculada ${ }^{206} \mathrm{~Pb} /{ }^{238} \mathrm{U}$ de 
81.86 $\pm 0.61 \mathrm{Ma}(\mathrm{MSWD}=1.18, \mathrm{n}=92)$, y valores $\mathrm{U} / \mathrm{Th}=0.3-1.21$, valores típicos de circones ígneos (Rubatto, 2002).

Para la muestra WSF (diorita), fueron analizados 18 granos con tamaño variable entre 50 y 200 $\mu \mathrm{m}$ y valores $\mathrm{Th} / \mathrm{U}=0.61-0.31$, típicos de circones magmáticos, (Figura 8). Esta muestra presentó circones ígneos euhedrales, con crecimiento oscilatorio, cristalizados sin núcleos heredados y una edad ${ }^{206} \mathrm{~Pb} /{ }^{238} \mathrm{U}$ de $78.4 \pm 6.4 \mathrm{Ma}(\mathrm{n}=12)$ (Figura 8). La mayoría de los datos de este análisis fueron discordantes, debido principalmente a proporciones altas de $206 \mathrm{~Pb}$.

En la muestra W68SC (cuarzodiorita) fueron analizados 27 granos con tamaños entre 150 y 400 $\mu \mathrm{m}$ y valores $\mathrm{Th} / \mathrm{U}=0.93-0.54$ típicos de circones magmáticos (Rubatto, 2002), (Figura 8), de los cuales fueron concordantes 18 disparos. Presentó circones ígneos euhedrales, con crecimiento oscilatorio, bien cristalizados y sin núcleos heredados y se calculó una edad ${ }^{206} \mathrm{~Pb} /{ }^{238} \mathrm{U}$ de $79 \pm 2.4 \mathrm{Ma}$ (Figura 8). Todos los análisis presentan una alta concordancia con edades semejantes (Figura 8).

En la muestra W64SA (diorita), fueron analizados 18 granos de circón, con tamaños entre 150 y $300 \mu \mathrm{m}$ y valores $\mathrm{Th} / \mathrm{U}=0.78-0.19$, típicos de circones magmáticos (Rubatto, 2002; Figura 8). La muestra presentó circones ígneos euhedrales, con crecimiento oscilatorio, bien cristalizados (Vavra et al., 1999) y sin núcleos heredados y una edad ${ }^{206} \mathrm{~Pb} /{ }^{238} \mathrm{U}$ de $79 \pm 14 \mathrm{Ma}$ (Figura 8).

La muestra WTrCa (diorita) corresponde a una diorita con abundantes xenolitos de la Granulita de Pantanillo y cortada por diques asociadas al magmatismo terciario presente en la zona. En esta fueron analizados 19 circones con tamaños entre 100 y $300 \mu \mathrm{m}$ y valores $\mathrm{Th} / \mathrm{U}=0.82-0.29$, típicos de circones magmáticos (Rubatto, 2002; Figura 8), ígneos euhedrales, con crecimiento oscilatorio, cristalizados y sin núcleos heredados y una edad ${ }^{206} \mathrm{~Pb} /{ }^{238} \mathrm{U}$ de $81.4 \pm 2 \mathrm{Ma}$.

\subsubsection{STOCK DE BURITICÁ}

La muestra WBR (tonalita) presentó una edad ${ }^{206} \mathrm{~Pb} /{ }^{238} \mathrm{U}$, concordante de $93.9 \pm 3 \mathrm{Ma}$, con 18 granos analizados. Los granos son euhedrales, sin núcleos heredados y tamaños entre 100 y $500 \mu \mathrm{m}$ y valores $\mathrm{Th} / \mathrm{U}=1.17-0.30$ asociados a circones magmáticos (Rubatto, 2002; Figura 9). La edad obtenida fue menor, de la de 102 Ma reportada por Weber et al., (2015); pero consistentemente mayor con las obtenidas en el Gabro de Santa Fe.

\section{Discusión y conclusiones}

Nuevos datos geoquímicos, geocronológicos y cartografía geológica detallada de los plutones que intruyen a ambos márgenes de la Falla Sabanalarga (Hall et al., 1972; Rodríguez et al., 2012a; Correa et al., 2018), permitieron separar con mayores argumentos el denominado "Batolito de Sabanalarga" (González et al., 1976; Álvarez y González, 1978; González, 2002; Rodríguez et al., 2012a). En Cuarzodiorita de Sabanalarga y Gabro de Santa Fe, continuando la separación planteada por Nivia y Gómez (2005) hecha en base a diferencias petrográficas y relaciones de campo respecto a la definición original para el Plutón de Sabanalarga de Hall et al., (1972); Álvarez et al., (1975); Mejía et al., (1983).

Asimismo, relaciones de campo evidenciadas durante la cartografía geológica permitieron identificar dos bloques tectónicos autónomos, intruidos por plutones de diferente composición y edad similar a ambos márgenes de la Falla Sabanalarga. Los análisis demostraron que, al este la Cuarzodiorita de Sabanalarga, un cuerpo de composición principalmente tonalita y con edades ígneas de $76.7 \pm 2.4$, 85.4 $\pm 2.4,74.6 \pm 7.6,76.2 \pm 3.4,71.6 \pm 1.2,71.5 \pm 2.4$ $\mathrm{Ma}$, intruye rocas metamórficas en facie esquisto verde asociadas al Complejo Cajamarca (terreno Tahami). Del mismo modo, al oeste el Gabro de Santa Fe de composición gabro-gabrodiorita y con edades ígneas de $79.71 \pm 0.85,86.7 \pm 1.6$, $81.86 \pm 0.61,78.4 \pm 6.4,79 \pm 2.4,79 \pm 14,81.4 \pm 2$ $\mathrm{Ma}$, se encuentra intruyendo rocas volcánicas básicas de ambiente oceánico de la Formación Barroso (terreno Caribe) y con algunos cuerpos de xenolitos en facie granulita de la Anfibolita de Pantanillo (Cardona, 2010; Rodríguez et al.,

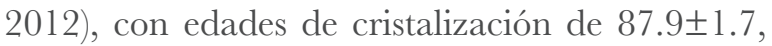




\section{Cuarzodiorita de Sabanalarga}
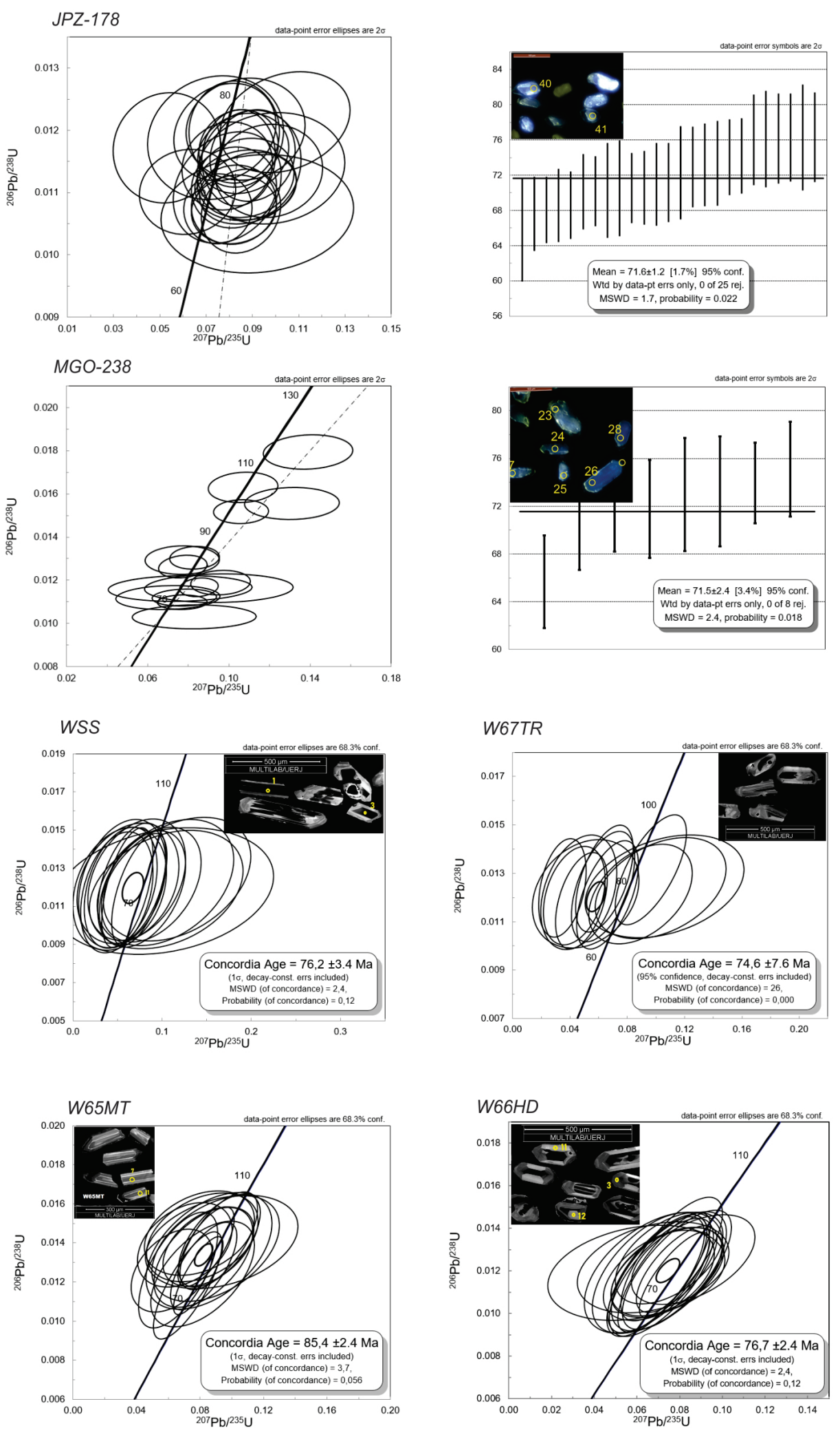

Figura 7 Edades U-Pb muestras JPZ-178, MGO-238, WSS, W67TR, W65MT, W66HD. 
Gabro de Santa Fe
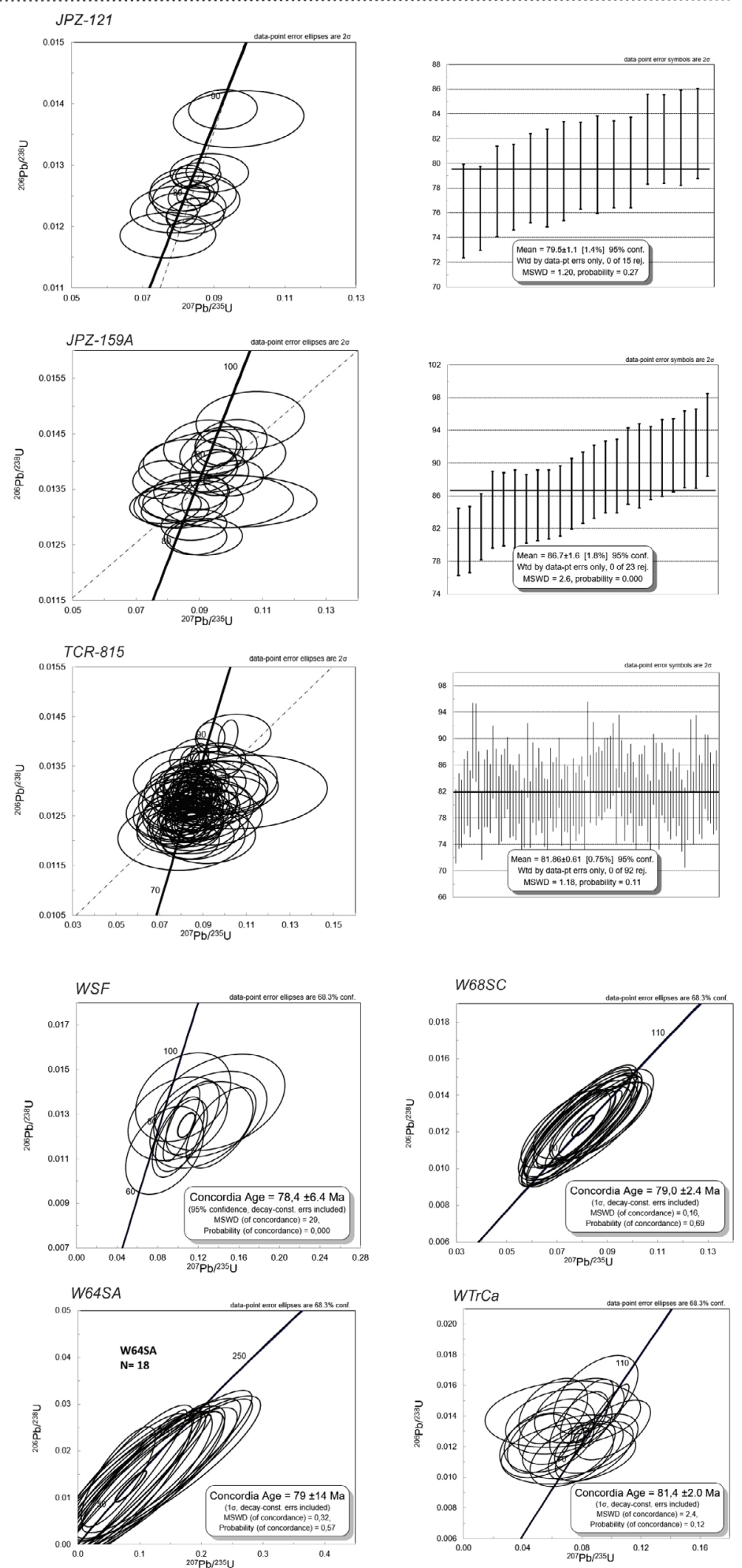

Figura 8 Edades U-Pb muestras JPZ-121, JPZ-159A, TCR-815, WSF, W68SC, W64SA, WTrCa. 


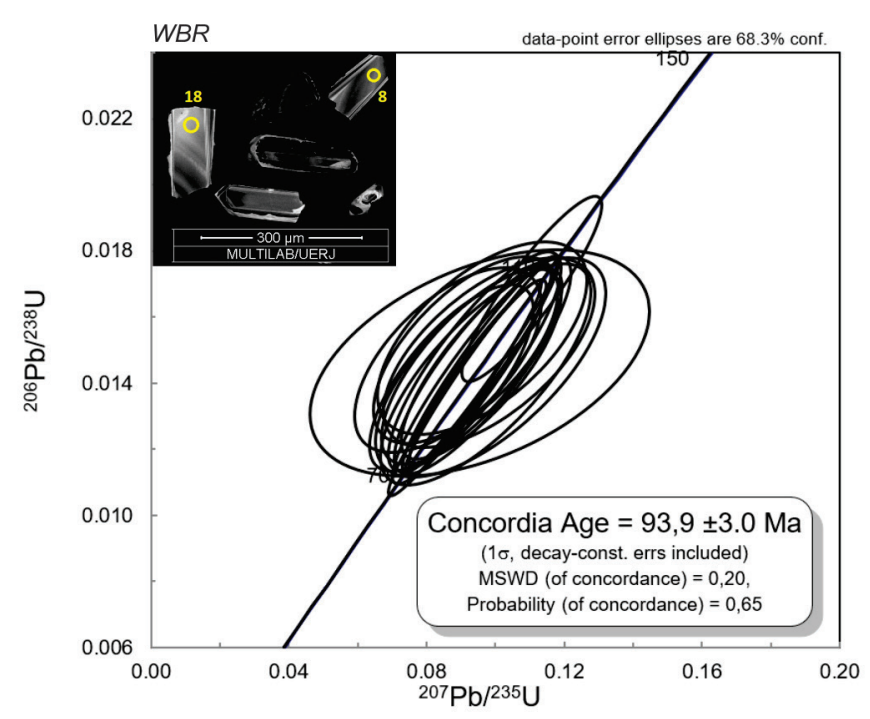

Figura 9 Edades U-Pb muestra WBR.

$84.2 \pm 0.69$ y $80.9 \pm 1.2$ Ma (Correa et al., 2018) y asociados a las raíces del arco volcánico engrosado (Toro-Toro et al., 2020) .

Entre ambos plutones y al interior de las trazas de la falla de Sabanalarga, se encuentran un cinturón de bloques de basaltos, esquistos, rocas ultramáficas y milonitas que varían en el grado de su deformación. Los dos intrusivos presentan anomalías de $\mathrm{Nb}-\mathrm{Ti}$, patrones de HFSE y REE en los diagramas multielementales característicos de rocas generadas en ambientes de subducción. Sin embargo, tienen algunas diferencias: la Cuarzodiorita de Sabanalarga presenta valores de $\mathrm{Sr}=78.6-504 \mathrm{ppm}, \mathrm{Y}=12-25 \mathrm{ppm}$ y razones $\mathrm{Sr} / \mathrm{Y}$ $=6.5-25.1$ y $\mathrm{La} / \mathrm{Yb}=4.4-5.9$ características de magmas no adakíticos; mientras tanto, el Gabro de Santa Fe presenta valores de $\mathrm{Sr}=151-732$ ppm, Y=7-20.9 ppm y razones $\mathrm{Sr} / \mathrm{Y}=9-122$ y $\mathrm{La} / \mathrm{Yb}=2.08-7.6$ afines con algunas características adakíticas (Kay y Kay, 2002). Además, en el diagrama de discriminación tectónica $(\mathrm{La} / \mathrm{Yb}) \mathrm{n}$ vs Sr/Y (Condie y Kroner, 2013) de la figura 6b se observa que las rocas asociadas a la Cuarzodiorita de Sabanalarga caen en el campo de los arcos continentales; mientras que las rocas del Gabro de Santa Fe caen entre los campos de arcos oceánicos y continentales ; sugiriendo la evolución a partir de un arco inmaduro.
Las diferencias de espesor cortical, basadas en valores La/Yb y Sr/Y (Profeta et al., 2015) para la Cuarzodiorita de Sabanalarga, arrojan espesores entre 23-29 km y de 17-52 Km para la corteza Gabro de Santa Fe; datos que indican que ambos plutones se emplazaron en cortezas de diferente espesor; una continental de 23-29 km (al este del SFGR) y una corteza oceánica engrosada de 15-52 km (al oeste del SFGR). En la margen oriental asociada al magmatismo tipo Batolito Antioqueño-Stock de Ovejas (Leal-Mejía,2011; Duque-Trujillo et al., 2019) y en el margen occidental asociada a la formación de granitos sobre corteza tipo Plateau en ambientes de subducción o fusión parcial de la corteza oceánica (Weber et al., 2015).

Las muestras de la Cuarzodiorita de Sabanalarga presentan valores de Zr hasta 150 ppm y las del Gabro de Santa Fe presenta valores desde 25-111 ppm. El contenido de Zr en los plutones estudiados muestran que la posibilidad de que el magma sea saturado en $\mathrm{Zr}$ es mayor para la Cuarzodiorita de Sabanalarga; esto por estar emplazada en un ambiente continental. Mientras que para el Gabro de Santa Fe, la saturación de Zr es menor en la mayoría de las muestras: debido a su ambiente oceánico (Weber et al.,2015). Las bajas cantidades de Zr en el Gabro de Santa Fe 


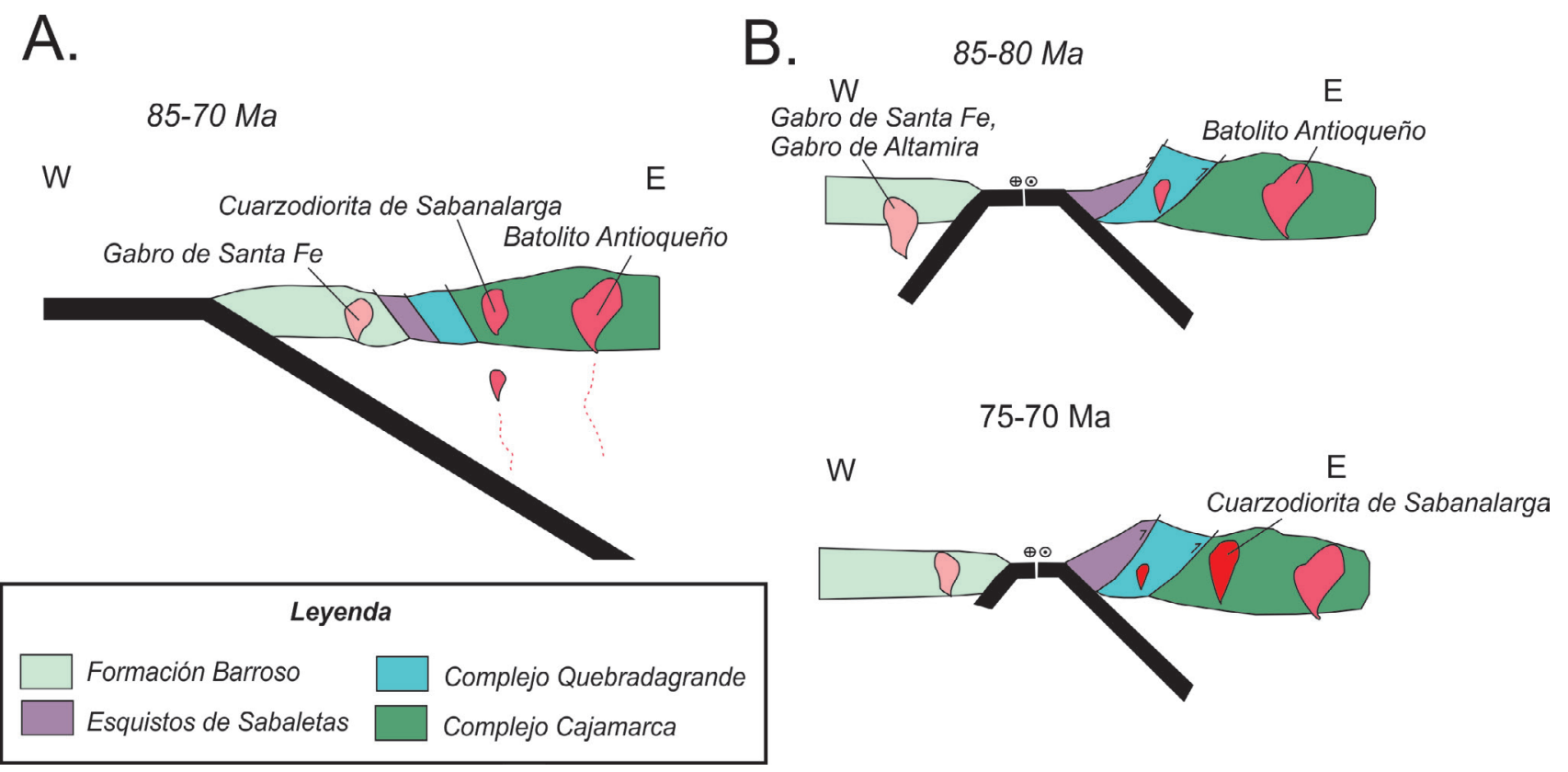

Figura 10 Modelos tectónicos A) Modelo de subducción con migración de la trinchera al occidente (Modificado de Rodríguez et al., 2012). B) Modelo de doble subducción (Modificado de Villagómez et al., 201 1; Jaramillo et al., 2017).

explican la dificultad para la separación de circones presentada por las rocas de dicha unidad.

Los datos U-Pb obtenidos en este trabajo indican que ambos cuerpos cristalizaron en el Cretácico Superior. La Cuarzodiorita de Sabanalarga presenta dos grupos de edades, posiblemente correspondientes a dos pulsos: el más joven está entre 71.5 y $76.7 \mathrm{Ma}$ (con una media ponderada de $72.8 \pm 2.9 \mathrm{Ma})$ y un dato más antiguo de $85 \mathrm{Ma}$. La morfología de cristales de circón (Giraldo, 2017) y los datos isotópicos ${ }^{87} \mathrm{Sr} /{ }^{86} \mathrm{Sr}=0.70379-0.70379$ y $\mathcal{E}_{\mathrm{Nd}}=+6.58$ (Ordoñez-Carmona, 2001), permiten asociar este pulso al Stock de Altavista con ${ }^{87} \mathrm{Sr} /{ }^{86} \mathrm{Sr}=0.70292$, $0.70456,0.70743$ y $\varepsilon_{\mathrm{Nd}}=+7.4,+9.8,+2.6$ (Correa et al., 2006).

El Gabro de Santa Fe presenta edades entre 78.4 y $81.8 \mathrm{Ma}$ (con una media ponderada de $81.0 \pm 1.4 \mathrm{Ma}$ ) y una edad de $86.7 \pm 1.6 \mathrm{Ma}$, similares a las edades de 80 y 87 Ma de la Granulita de Pantanillo. Guerpos satélites asociados al Gabro de Santa Fe, como el Stock de Buriticá, tienen edades U-Pb entre 93-100 Ma (Weber et al., 2015). Ambos cuerpos presentan relaciones isotópicas de ${ }^{87} \mathrm{Sr} /{ }^{86} \mathrm{Sr}=0.7037$ y $\mathcal{E}_{\mathrm{Nd}}=+7$ (Weber et al., 2015), ${ }^{87} \mathrm{Sr} /{ }^{86} \mathrm{Sr}=0.70469$ y $\varepsilon_{\mathrm{Nd}}=+6.67,+6,81$
(Ordoñez-Carmona, 2001), valores isotópicos primitivos (Weber et al., 2015).

Ambos plutones presentan una diferencia de aproximadamente 8-10 Ma en su cristalización, siendo un poco más joven los Plutones al Este de la Falla Sabanalarga y asociados a una de las primeras etapas del magmatismo del Batolito Antioqueño, entre 81-72 Ma (Stock de Ovejas) (Leal-Mejía, 2011; Duque-Trujillo et al., 2019). La edad de cristalización del Gabro de Santa Fe está asociada a cuerpos intrusivos de afinidad tonalítica en el Plateau Caribe menores a $100 \mathrm{Ma}$, como el Gabro de Altamira, Granito Pujilì, el Batolito de Buga y el Batolito de Aruba (White et al., 1999, Vallejo, 2007; Villagómez et al., 2011; ZapataVillada et al., 2017).

La existencia de dos arcos contemporáneos podría ser explicado en base a dos modelos geológicos, una subducción única o una doble subducción tipo Molucca. El modelo de subducción única explicaría dos magmas con características distintas; esto al considerar la existencia de la trinchera al occidente de la Formación Barroso, con fusión de placa a diferentes profundidades (Rodríguez et al., 2012a). Debido a la reología y composición de los materiales intruidos, al occidente el basa- 
mento engrosado del Plateau Caribe y al oriente el basamento metamórfico pre-cretáceo del terreno Tahamí, es probable que se generaran magmas de diferente afinidad geoquímica (Figura 10A). En este modelo sería necesario explicar las unidades que se encuentran entre las Fallas Cauca-Oeste y Falla San Jerónimo, como los Esquistos de Sabaletas y el Complejo Quebradagrande, (Figura 10A). Las evidencias de campo, como la abstención de cornubianas y la no evidencia de intrusión de la Cuarzodiorita de Sabanalarga en los Esquistos de Sabaletas y el Complejo Quebradagrande, sugieren que estas dos unidades fueron adosados a la margen posterior a su acreción. Villagómez et al., (2011) presenta evidencias de intrusiones de c.a de 80 Ma del Plutón de Córdoba sobre rocas del Complejo Quebradagrande. Sin embargo, los Esquistos de Sabaletas con edades máximas de depositación de $76 \mathrm{Ma}$ (Zapata-Villada, 2018) no se observan intruidos por cuerpos cretáceos c.a 80-72 Ma; evidencia que sugiere que esta secuencia metamórfica de bajo grado no se encontraba acrecionada a la margen continental en este periodo (Figura 10A).

Por otro lado, la subducción opuesta tipo Molucca (Hall y Wilson, 2000; Zhang et al., 2017) involucra la colisión de dos arcos oceánicos, sin embargo, en el Noroccidente de Suramérica comprende la colisión de un arco oceánico y arco continental, basado en reconstrucciones cinemáticas de la Placa Caribe de régimen oblicuo transpresivo (Kennan and Pindel, 2009, Villagómez et al., 2011; Jaramillo et al., 2017). Esta doble subducción, sugiere la existencia de una zona de subducción desarrollada al occidente sobre el Plateau Caribe y otra al oriente sobre el basamento pre-Cretácico del terreno Tahami, (Figura 10B; Vallejo et al., 2006; Villagómez et al., 2011; Wright and Wyld, 2011; Weber et al., 2015, Jaramillo et al., 2017) y permite explicar fragmentos de unidades alóctonas existentes entre ambos arcos.

Las rápidas tasas de exhumación entre 80-73 Ma del Norte de Suramérica (Villagómez y Spikings, 2013), los cambios en la sedimentación de las cuencas tras arco (Villamil, 1999; Bayona, 2018), y un cambio importante en la composición del magmatismo del arco continental en la Cordillera Central c.a 73 Ma (Jaramillo et al., 2017), sugieren una colisión de un arco oceánico y un arco continental (Jaramillo et al., 2017, Pardo-Trujillo et al., 2020). Además, el registro estratigráfico y proveniencia de parte del Miembro Urrao, que suprayase facies vulcanoclasticas de la Formación Barroso, es también coetáneo con la colisión de ambos arcos (Pardo-Trujillo et al., 2020).

Finalmente, a pesar de los grandes avances en geología regional, trabajos estratigráficos y geocronología U-Pb en los últimos años, la poca cantidad de evidencias estructurales, la escasa información isotópica de intrusivos a ambos lados la Falla Sabanalarga o Falla Cauca Oeste (SFCR) y la perdida de kilómetros de corteza producto del régimen transpresivo oblicuo del Cretáceo (Kennan and Pindell, 2009, Moreno- Sanchez et al., 2016) hacen necesario trabajos más rigurosos en el área de estudio para poder establecer un único escenario tectónico posible.

\section{Agradecimientos}

Este trabajo ha sido financiado por el Servicio Geológico Colombiano, el fondo CAPES (Coordenação de aperfeiçoamento de pessoal de nivel superior), FAPERJ (Fundação de Amparo à Pesquisa do Estado do Rio de Janeiro) y la Universidad del Estado de Rio de Janeiro. Un agradecimiento especial por el apoyo en campo a Francy Ortiz, Tomas Correa, Angela Viviana Rincón, Faustino Mosquera, Manuel Castro (Grupo de Cartografía 1:50.0000 del Grupo de Estudios Geológicos Especiales, Medellín), y a la Universidad Nacional de Colombia, particularmente a los profesores Oswaldo Ordóñez y Jorge Julián Restrepo.

\section{Referencias}

Álvarez, E. y González, H. 1978, Geología y geoquímica del Cuadrángulo I-7 Urrao, Mapa escala 1:100.000: Medellín, INGEOMINAS, 347 p.

Álvarez, J., Rico, H., Vásquez, H., Hall, R, Blade, 
L, 1975, Geological map of the Yarumal Quadrangle (H-8) and part of the Ituango Quadrangle (H-7), Escala 1:100.000, Bogotá, Colombia. INGEOMINAS.

Barrero, D., 1979, Geology of the Central Western Cordillera, west of Buga and Roldanillo, Colombia: Publicaciones Geologicas Especiales del Ingeominas, 4, 1-75.

Bayona, G., Cardona, A., Jaramillo, G., Mora, A., Montes, C., Valencia, V., Ayala, C., Montenegro, O., Ibañez, M., 2012. Early Paleogene magmatism in the northern Andes: insights on the effects of Oceanic Plateau-continent convergence: Earth and Planetary Science Letters, 331-332, 97-111. https://doi.org/10.1016/j.epsl.2012.03.015

Bayona, G., 2018, El inicio de la emergencia en los Andes del norte: una perspectiva a partir del registro tectónico-sedimentológico del Coniaciano al Paleoceno: Revista de la Academia Colombiana de Ciencias Exactas, Fisicas y Naturales. 42 (165), 364-378. https://doi.org/10.18257/raccefyn.632

Blanco-Quintero , I., García-Casco, A., Toro, L., Moreno, M., Ruiz, E., Vinasco, C., Cardona, A., Lázaro, C., Morata, D., 2014, Late Jurassic terrane collision in the northwestern margin of Gondwana (Cajamarca Complex,eastern flank of the Central Cordillera, Colombia): International Geology Review, 56 (15), 18521872. https://doi.org/10.1080/00206814.2 014.963710

Botero, A., 1963, Contribución al conocimiento de la geología de la zona central de Antíoquia: Anales Facultad de Minas, Medellín, Colombia, 101 p.

Bustamante, C., Cardona, A., Archanjo, C.J., Bayona, G., Lara, M., Valencia, V., 2016, Geochemistry and Isotopic Signatures of Paleogene Plutonic and Detrital Rocks of the Northern Andes of Colombia: a Record of Post-collisional Arc Magmatism: Lithos, 277, 199-209. https://doi.org/10.1016/j. lithos.2016.11.025

Bustamante, A., Juliani, C., Hall, C.M., Essene, E,J. 2011. ${ }^{40} \mathrm{Ar} /{ }^{39} \mathrm{Ar}$ ages from blueschists of the Jambaló región, Central Cordillera of Colombia: Implications on the styles of accretion in the Northern Andes: Geologica Acta, 9, 351-362. https://doi. org/10.1344/105.000001697

Aiglsperger, T., Proenza, J.A., Zaccarini, F., Labrador, M., Navarro-Ciurana, D., 2011, Looking for needles in a haystack: how to find PGM in laterites by using hydroseparation techniques: Revista de La Sociedad Española de Mineralogía, 15, 23-24.

Buchs, D., Kerr, A.C., Brims, J.C., Zapata-Villada, J.P., Correa-Restrepo, T., Rodríguez, G., 2018. Evidence for subaerial development of the Caribbean oceanic plateau in the Late Cretaceous and palaeo-environmental implications: Earth and Planetary Science Letters, 499, 62-73. https://doi. org/10.1016/j.epsl.2018.07.020

Cardona, J.D., 2010, Análisis petrográfico de rocas metamórficas al noroccidente de Santa Fe de Antioquia en el llamado Batolito de Sabanalarga al occidente de la falla Cauca Almaguer: Medellín, Universidad Nacional de Colombia Sede Medellín, Tesis de Grado, 72p.

Castro, N., Feininger,T., 1965, Geología en la región entre Buriticá y Santa Fe de Antioquia, Con especial referencia a la geología económica de un cuerpo andesítico. INGEOMINAS, Medellín, Informe Interno, 37 p.

Cediel, F., Shaw, R., Caceres, C., 2003, Tectonic Assembly of the Northern Andean block, in The Circum-Gulf of Mexico and the Caribbean: Hydrocarbon Habitats, Basin Formation and Plate Tectonics: AAPG Bulletin, 79, 815 848. https://doi.org/10.1306/M79877C37

Chemale, F., Kawashita, K., Dussin, I. A., Nunes Avila, J., Justino, D., Bertotti, A., 2012, U-Pb zircon in situ dating with LA-MC-ICPMS using mixed detector configuration: Anais da Academia Brasileira de Ciencias, 84 (2), 275-295.https://doi.org/10.1590/ s0001-37652012005000032

Cochrane, R., 2013, U-Pb thermochronology, geochronology and geochemistry of NW South America: rift to drift transition, active 
margin dynamics and implications for the volume balance of continents: University of Geneva, Switzerlan, Thése de doctorat, 191 p. 10.13097/archive-ouverte/unige:30029

Correa M., A.M., Pimentel, M., Restrepo, J.J., Nilson, A., Ordoñez, O., Martens, U., Laux, J.E., Junges, S., 2006, U-Pb zircon ages and $\mathrm{Nd}-\mathrm{Sr}$ isotopes of Altavista Stock and the San Diego Gabbro: New insights of Cretaceous arc magmatism in the Colombian Andes, en V SSAGI: Punta del Este, Uruguay.

Correa, T., Zapata-Villada., J, P., Rincón, A., Obando, M., Ortiz, F., Rodríguez, G., 2017, Edades U-Pb y Ar-Ar obtenidas durante la cartografía 1:50.000 del borde occidental de la Plancha 130, Santa Fe de Antioquía, en XVI Congreso Colombiano de Geología: Santa Marta, Colombia. Abstract, 1223-1228.

Correa, T., Obando, M., Zapata- Villada, J., Rincón, A., Ortiz, F., Rodríguez, G., Cetina, L., 2018, Geología del borde Occidental de la plancha 130 Santa fe de Antioquia, Escala 1:50,000: Medellín, Servicio Geológico Colombiano, Memoria Explicativa, 552 p. https://doi.org/10.32685/10.143.2018.754

Condie, K.G.,Kröner, A., 2013, The building blocks of continental crust: evidence for a major change in the tectonic setting of continental growth at the end of the Archean: Gondwana Research, 23, 394-402. https:// doi.org/10.1016/j.gr.2011.09.011

Coyner, S.J., Kamenov, G.D., Mueller, P.A., Rao, V., and Foster, D.A., 2004, FG-1: a zircon reference standard for the determination of Hf isotopic compositions via laser ablation ICP-MS, en American Geophysical Union, Fall Meeting: San Francisco, USA.

Castro, A., 2014, The Off-Crust Origin of Granite Batholiths, Geoscience Frontiers, 5, 63 -75. https://doi.org/10.1016/j.gsf.2013.06.006

Duque-Trujillo, J., Bustamante,C., Solari, L., Gómez-Mafla, A., Toro-Villegas, G., Hoyos, S., 2019, Reviewing the Antioquia batholith ans satellite bodies: a record of Late Cretaceous to Eocene syn- to postcollisional arc magmatism in the central
Cordillera of Colombia: Andean Geology 46 (1), 82-101. https://doi.org/10.5027/ andgeov46n1-3120

Flórez, J., Valencia, A, 2006, Cartografía geológica de $137 \mathrm{~km}^{2}$ entre los municipios de Santa Fe de Antioquia y Olaya, Departamento de Antioquia: Colombia, Bogotá, D.C. Universidad Nacional de Colombia. Tesis de grado.

Etayo, F., González, H., Álvarez, J., 1980, Med Albian ammonites from northern Western Cordillera, Colombia: Geología Norandina, 2, 25-30.

Giraldo, W., 2017, Novas idades U-Pb (LA-ICPMS) de rochas granitoides na região de Sabanalarga (Colômbia) e sua correlação com a evolução da Placa do Caribe: Rio de Janeiro, Brasil, Universidade do Estado do Rio de Janeiro, Tesis de Grado M. Sc, 90 p.

González, H., Londoño, A.C., 2002, Catálogo de las unidades litoestratigráficas de Colombia, Batólito de Sabanalarga, Cordillera Occidental departamento de Antioquia, INGEOMINAS: Medellín, Informe técnico, $12 \mathrm{p}$.

González, H., Restrepo, J.J., Toussaint, J.F., Linares E., 1976, Edad radiométrica K-Ar del Batolito de Sabanalarga : Publicación Especial de Geología, 8, 1-5.

González H., Londoño, G. 1998, Edades K-Ar en algunos cuerpos plutónicos del Graben Cauca-Patía y norte de la Cordillera Occidental: Geología Colombiana, 23, 117 131. https://doi.org/10.15446/gc

Gómez, J., Nivia, A., Montes, N.E., Jimenez, D.M., Tejada, M.L., Sepulveda, J., Osorio, J.A., Gaona, T., Diederix, H., Uribe, H., Mora, M., 2007, Geological map of Colombia, Escala 1:1'000.000: Bogotá, INGEOMINAS, 2 p.

Guiral,J., Rincón, J., Ordoñez, O., 2015, Geología de la porción sur del Batolito de Sabanalarga, Implicaciones para la teoría de terrenos al occidente de Colombia: Boletín de Ciencias de la Tierra, 38, 41 - 48. https://doi. org/10.15446/rbct.n38.46367 
Geoestudios-Ingeominas, 2005, Complementación geológica, geoquímica y geofísica de la parte occidental de las planchas 130 Santa Fé de Antioquia y 146 Medellín Occidental. Escala 1:100,000: INGEOMINAS, Informe técnico, $276 \mathrm{p}$.

Gómez, J., Montes N. E., Nivia, Á., Diederix, H., 2015, Mapa Geológico de Colombia 2015, Escala 1:500,000: Bogotá, Servicio Geológico Colombiano, 2 p.

Hall, R.; Álvarez, J.; Rico, II., 1972, Geología de los departamentos de Antioquia y Caldas (Sub-zona IIA): Bol, Geol, Ingeominas, 20 (1), $85 \mathrm{p}$.

Hall, R., Wilson, M.E.J., 2000, Neogene sutures in eastern Indonesia: Journal Asian Earth Sciences, 18 (6), 781-808. https://doi. org/10.1016/s1367-9120(00)00040-7

Ibáñez Mejía, M., Tassinari, G.G.G., Jaramillo, J.M., 2007, U-pb Zircon Ages of the Antioquian Batholith: Geochronological Constraints of Late Cretaceous Magmatism in the Central Andes of Colombia, en XI Congreso Colombiano de Geología: Bucaramanga, $11 \mathrm{p}$.

Irvine, T.N.,Baragar, W.R. 1971, A guide to chemical classification of the common volcanic rocks: Canadian Journal of Earth Sciences 8, 523-548. https://doi. org/10.1139/e71-055

Jaramillo, J.S., Cardona, A., León, S., Valencia, V., Vinasco, G., 2017. Geochemistry and geochronology from Cretaceous magmatic andsedimentary rocks at $6^{\circ} 35^{\prime} 0 \mathrm{~N}$, western flank of the Central cordillera (Colombian Andes): Magmatic record of arc growth and collision: Journal of South American Earth Sciences, 76, 460-481. ttps://doi. org/10.1016/j.jsames.2017.04.012

Jackson, S.E., Pearson, N.J., Griffin, W.L., Belousova, E.A., 2004, The application of laser ablation-inductively coupled plasma-mass spectrometry to in situ $\mathrm{U}-\mathrm{Pb}$ zircon geochronology: Chemical Geology, 211, 47- 69. https://doi.org/10.1016/j. chemgeo.2004.06.017
Jones, D. L., Cox, A., Coney, P.,Beck, M, 1982, The growth of western North America: Scientific America, 247, 70-84.

Kay, R.W., Kay, S.M., 2002, Andean adakites: three ways to make them: Acta Petrologica Sinica, 18(3), 303-311.

Kennan, L., Pindell, J., 2009, Dextral shear, terrane accretion and basin formation in the Northern Andes: best explained by interaction with a Pacific-derived Caribbean Plate? In: James, K.H., Lorente, M.A., Pindell, J.L. (Eds.), The Origin and Evolution of the Caribbean Plate: Geological Society of London, Special Publications 328, 487-531 https://doi.org/10.5724/gcs.07.27.0649

Leal-Mejía, H., 2011, Phanerozoic gold metallogeny in the Colombian Andes: A Tectono-Magmatic approach: Barcelona, España, Universidad de Barcelona, PhD thesis, $1000 \mathrm{p}$.

Ludwig, K. R., 2000, Decay constant errors in $\mathrm{U}-\mathrm{Pb}$ concordia-intercept ages: Chemical Geology, 166, 315-318. https://doi. org/10.1016/s0009-2541(99)00219-3

Ludwig, K.R., 2012, User's Manual for Isoplot 3.75-4.15, A Geochronological Toolkit Microsoft Excel, Berkeley Geochronology Center, Special Publication, 75p.

Maya, M., Gonzáles, H., 1995, Unidades Litodémicas de La Cordillera Central de Colombia: Boletín Geológico, 35 (2-3), 43-57. https://doi.org/10.32685/10.143.1995.708

Moreno-Sánchez, M., Pardo-Trujillo, A., 2003, Stratigraphical and sedimentological contrains on western Colombia: implications on the evolution of the Caribbean Plate. The Circum-Gulf of Mexico and the Caribbean: hydrocarbon habitats, basin formation and plate tectonics. C. Bartolini, R. T. Buffler and J.F Blickwede: American Association of Petroleum Geologist, Memoir 79,891-924. https://doi.org/10.1306/M79877C40

Mora-Bohórquez, J. A., Ibánez-Mejía, M., Oncken, O., de Freitas, M., Vélez, V., Mesa, A., Serna, L., 2017, Structure and age of the Lower Magdalena Valley basin basement, 
northern Colombia: New reflection-seismic and U-Pb-Hf insights into the termination of the central andes against the Caribbean basin: Journal of South American Earth Sciences, 74 , 1-26. https://doi.org/10.1016/j. jsames.2017.01.001

Moreno-Sánchez, M., Hincapié, J., Ossa, M., Augusto, C., Toro Toro, L.M., 2016, Caracterización geológico-estructural de algunas zonas de cizalla en el Complejo Quebradagrande en los alrededores de Manizales y Villamaría: Boletín de Geología, 38 (4), 15-27. https://doi.org/10.18273/ revbol.v38n4-2016001

Middlemost, E., 1994, Naming materials in the magma/igneous rock system: EarthScience Reviews, 37, 215-224. https://doi. org/10.1016/0012-8252(94)90029-9

Mejía, M., Álvarez, E., González, H., Grosse, E., 1983, Mapa Geológico de Plancha 146 Medellín Occidental, Escala 1:100,000: Bogotá, INGEOMINAS, Mapa.

Nakamura, N., 1974, Determination of REE, $\mathrm{Ba}, \mathrm{Fe}, \mathrm{Mg}, \mathrm{Na}$ and $\mathrm{K}$ in carbonaceous and ordinary chondrites: Geochimica and Cosmochimica Acta, 38, 757-775. https:// doi.org/10.1016/0016-7037(74)90149-5

Nivia, A., Gómez, J., 2005, El Gabro Santa Fe de Antioquia y la Cuarzodiorita Sabanalarga, una propuesta de nomenclatura litoestratigráfica para dos cuerpos plutónicos diferentes agrupados previamente como Batolito de Sabanalarga en el departamento de Antioquia, Colombia, en X Congreso Colombiano de Geología, Bogotá, Colombia, 11 p.

Ordoñez, O., Pimentel, M., Laux, J.H., 2008, Edades U-Pb del Batolito Antioqueño: Boletín de Ciencias de la Tierra, 1 (22), 129-130.

Ordoñez-Carmona, O., 2001, Caractericao isotopica $\mathrm{Rb}-\mathrm{Sr}$ e $\mathrm{Sm}-\mathrm{Nd}$ dos principais eventos magmaticos nos andes colombinos: Brasilia-DF, Brasil, Universidad de Brasilia, Tese de doutorado, $177 \mathrm{p}$.
Ordoñez-Carmona, O., Pimentel, M. M., 2002, $\mathrm{Rb}-\mathrm{Sr}$ and $\mathrm{Sm}-\mathrm{Nd}$ isotopic study of the Puquí complex, Colombian Andes: Journal of South American Earth Sciences, 15 (2), 173-182 https://doi.org/10.1016/ s0895-9811(02)00017-2

Paton, G., Woodhead, J.D., Hellstrom, J.C., Hergt, J.M., Greig, A., Maas, R., 2010, Improved laser a b l a t i o $n$ U-Pb zircon g e o c h r o n o l o g y through robust downhole fractionation correction: Geochemistry, Geophysics, Geosystems, 11(3), 1-36. https://doi. org/10.1029/2009gc002618

Pardo-Trujillo, A., Cardona, A,, Giraldo,A.S,. León,S., Vallejo, D.F., Trejos-Tamayo, R., Plata,A,. Ceballo, J., Echeverry, S., BarbosaEspitia, A., Slattery, J., Salazar-Ríos, A ., Botello, G.E., Gelis, S.A, Osorio-Granada, E., Giraldo-Villegas, G.A., 2020, Sedimentary record of the Cretaceous-Paleocene arccontinent collision in the northwestern Colombian Andes: Insights from stratigraphic and provenance constraints: Sedimentary Geology, 410, 105627. https://doi. org/10.1016/j.sedgeo.2020.105627

Peña-Urueña, M.L., Muñoz-Rocha, J.A., Urueña, C.L., 2018, Laboratorio de Geocronología en el Servicio Geológico Colombiano: avances sobre datación $\mathrm{U}-\mathrm{Pb}$ en circones mediante la técnica LA-ICP-MS: Boletín Geológico, 44, 3956. https://doi.org/10.32685/0120-1425/ boletingeo.44.2018.7

Pecerillo, A., Taylor, S. R., 1976, Geochemistry of Eocene Calc-alkaline volcanic rocks from Kastamonir area, Northern Turkey: Contributions to Mineralogy and Petrology, 58, 63-81. https://doi.org/10.1007/ bf00384745

Pearce, J.A., 2008, Geochemical fingerprinting of oceanic basalts with applications to ophiolite classification and the search for Archean oceanic crust: Lithos, 100, 14-48. https:// doi.org/10.1016/j.lithos.2007.06.016 
Pindell, J., Kennan,L., Maresch,W. V., Stanek, K., Draper, G., Higgs, R., 2005, Plate kinematics and crustal dynamics of circum Caribbean arc continent interactions: Tectonic controls on basin development in proto-Caribbean margins: Special Papper Geological Society of America, 394, 7-52. https://doi. org/10.1130/0-8137-2394-9.7

Profeta, L., Ducea, M.N., Chapman, J.B., Paterson, S.R., Henriquez-Gonzales, S.M., Kirsch, M., Petrescu, L., DeCelles, P.G., 2015, Quantifying crustal thickness over time in magmatic arcs: Scientific Reports, 5: 17786, 1-7. https://doi.org/10.1038/ srep 17786

Rubatto, D., 2002, Zircon trace element geochemistry: distribution coefficients and the link between $\mathrm{U}-\mathrm{Pb}$ ages and metamorphism: Chemical Geology, 184, 123-138. https:// doi.org/10.1016/s0009-2541(01)00355-2

Restrepo, J.J., Toussaint, J.F., 1975, Edades radiométricas de algunas rocas de Antioquia, Colombia: Publicación Especial Geológica, 6, 24p.

Restrepo, J, J., Ordoñez-Carmona, O., Martes, U., Correa, A, M., 2009, Terrenos, complejos y provincias en la Cordillera Central de Colombia, en XII Congreso Colombiano de Geología: Paipa, Boyacá, 1-16.

Rodríguez, G., Arango, M.A., Bermúdez, J.G., 2012a, Batolito de Sabanalarga, plutonismo de arco en la zona de sutura entre las cortezas oceánica y continental de los Andes del Norte: Boletín Ciencias Tierra, 32, 81-98.

Rodríguez, G., González, I., Restrepo, J.J., Martens, U., Cardona, F., David, J., 2012b, Ocurrence of granulites in the northern part of the Western Cordillera of Colombia: Boletín de Geología, 34, 37-53.

Rodríguez, G., González, H., Zapata, G., Cossio, U., Correa , A., 2016, Geología de la plancha 147 Medellín Oriental, escala 1:5000: Servicio Geológico Colombiano, Memoria explicativa, 464p. https://doi. org/10.32685/10.143.2016.501
Rodríguez, G., Zapata, G. 1995, Exploración de metales base $(\mathrm{Cu}-\mathrm{Pb}-\mathrm{Zn})$ y oro en una faja al oeste del Municipio de Ituango: Medellín, INGEOMINAS, Informe 2186, 49 p.

Rodríguez, G., Arango, M.A., 2013, Barroso Formation: a Tholeiitic volcanic arc and San Jose de Urama diabases: a T-MORB Type accretionary prism in the northern segment of Western Cordillera of Colombia: Boletin Ciencias la Tierra 33, 17-38.

Simon, E.J., $\quad$ Pearson,N.J., Griffin,W.L., Belousova, E.A., 2004, The application of laser ablation-inductively coupled plasmamass spectrometry to in situ $\mathrm{U}-\mathrm{Pb}$ zircon geochronology: Chemical Geology, 211(12), 47-69. https://doi.org/10.1016/j. chemgeo.2004.06.017

Sláma, J., Košler, J., Condon, D.J., Crowley, J.L., Gerdes, A., Hanchar, J.M., Horstwood, M.S.A., Morris, G.A., Nasdala, L., Norberg, N., Schaltegger, U., Schoene, B., Tubrett, M.N., Whitehouse, M.J., 2008, Plešovice zircon - A new natural reference material for $\mathrm{U}-\mathrm{Pb}$ and $\mathrm{Hf}$ isotopic microanalysis: Chemical Geology, 249 (1-2), 1-35. doi: 10.1016/j.chemgeo.2007.11.005. https:// doi.org/10.1016/j.chemgeo.2007.11.005

Spikings, R., Cochrane, R., Villagómez, D., Van der Lelij, R., Vallejo, C., Winkler, W.,Beate, B., 2015, The geological history of northwestern south America: from pangaea to the early collision of the caribbean large igneous province (290-75 Ma): Gondwana Research, 27, 95-139. https://doi.org/10.1016/j. gr.2014.06.004

Stacey, J.S., Kramers, J.D., 1975, Approximation of terrestrial lead isotope evolution by a two-stage model: Earth and Planetary Science Letters, 26(2), 207-221. https://doi. org/10.1016/0012-82 1X(75)90088-6

Sun, S., Mcdonough, W., 1989, Chemical and isotropic systematics of oceanic basalts: implications for mantle composition and processes. Magmatism in ocean basin: Geologial Society Special Publication, 42, 
313-345. https://doi.org/10.1144/gsl. sp.1989.042.01.19

Suter, F., Sartori, M., Neuwerth, R., Gorin, G., 2008, Structural imprints at the front of the Chocó-Panamá indenter: Fiel data from the North Cauca alley Basin, Central Colombia: Tectonophysics, 460, 134-157. https://doi. org/10.1016/j.tecto.2008.07.015

Toro-Toro, L.M., Vallejo, D., Salazar-Ríos, André., Murcia, H., Osorio-Ocampo, S., García-Arias, M., Arredondo, C., 2020, Granulite rocks at the Western Cordillera of Colombia: Evidence of metamorphism in the Colombian Caribbean oceanic plateau: Journal of South Amrican Earth Sciences, 101, 102632. https://doi.org/10.1016/j. jsames.2020.102632

Toussaint, J., Restrepo, J., 1978, Edad Cretácea de una anfibolita granatífera de Pijao-Quindío: Boletín Ciencia de la Tierra, 17, 1.

Vallejo, G., Spikings, R.A., Luzieux,L., Winkler,W.,Chew, D., Page, L., 2006, The early interaction between the Caribbean Plateau and the NW South American Plate: Terra Nova, 18(4), 264-269.

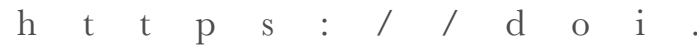
org/10.1111/j.1365-3121.2006.00688.x

Villagómez, D., Spikings, R., Magna, T., Kammer, A., Winkler, W., Beltran, A., 2011, Geochronology, geochemistry and tectonic evolution of the Western and Central cordilleras of Colombia: Lithos, 125, 875 - 896. https://doi.org/10.1016/j. lithos.2011.05.003

Villagómez, D., Spikings, R., 2013, Thermochronology and tectonics of the central and western cordilleras of Colombia: early cretaceous- tertiary evolution of the northern Andes: Lithos 168, 228-249. https://doi.org/10.1016/j. lithos.2012.12.008

Villamil, T., 1999, Campanian-Miocene tectonostratigraphy, depocenter evolution and basin development of Colombia and western Venezuela: Palaeogeography, Palaeoclimatology, Palaeoecology, 153,
239-275. https://doi.org/10.1016/ s0031-0182(99)00075-9

White, R.V., Tarney, J., Kerr, A.C., Saunders, A.D., Kempton, P.D., Pringle, M.S., Klaver, G.T., 1999, Modification of an oceanic plateau, Aruba, Dutch Caribbean: Implications for the generation of continental crust: Lithos, 46, 43-68. https://doi.org/10.1016/ s0024-4937(98)00061-9

Weber, M., Gomez-Tapias, J., Duarte, E.,Cardona, A., Vinasco-Vallejo, C.J., 201 1, Geochemistry of the Santa Fe Batholith, in NW Colombia: Remnant of an accreted Cretaceous arc, en Memorias XIVCongreso Latinoanericano de Geologia: Medellín, Colombia, 128-129.

Weber, M., Gómez-Tapias, J., Cardona, A., Duarte, E., Pardo-Trujillo, A., Valencia, V.A., 2015, Geochemistry of the Santa Fe batholith and buriticá tonalite in NW Colombia - evidence of subduction initiation beneath the colombian caribbean plateau: Journal of South America Earth Science, 62, 257-274. https://doi.org/10.1016/j. jsames.2015.04.002

Wright, J.E., Wyld, S. J,. 2011, Department of Geology, University of Georg Late Cretaceous subduction initiation on the eastern margin of the Caribbean-Colombian Oceanic Plateau: One Great Arc of the Caribbean: Geophere, 7 (2), 468-493. https://doi.org/10.1130/ges00577.1

Wetherill, G. W., 1956, Discordant uraniumlead ages: Transactions of the American Geophysical Union, 37, 320-326. https:// doi.org/10.1029/tr037i003p00320

Wiedenbeck, M., Allé, P., Corfu, F., Griffin, W., Meier, M., Oberli, F., von Quadt, A., Roddick, J.C. and Spiegel W., 1995, Three natural zircon standards for U-Th-Pb, Lu-Hf, trace element and REE analyses: Geostandards Newsletter, 19, 1-23. https:// doi.org/10.1111/j.1751-908x.1995. tb00147.x

Wiedenbeck, M., Hanchar, J.M., Peck, W.H., Sylvester, P., Valley, J., Whitehouse, M., Kronz, A., Morishita, Y., Nasdala, L., Fiebig, 
J., Franchi, I., Girard, J.P., Greenwood, R.C., Hinton, R., Kita, N., Mason, P.R.D., Norman, M., Ogasawara, M., Piccoli., P.M., Rhede, D., Satoh, H., Schulz-Dobrick, B., Skår, Ø., Spicuzza, M.J., Terada, K., Tindle, A., Togashi, S., Vennemann, T., Xie, Q, Zheng, Y.F, 2004, Further characterisation of the 91500 zircon crystal: Geostandards and Geoanalytical Research, 28(1), 9-39. https://doi.org/10.1111/j.1751908X.2004.tb01041.x.

Zapata, S., 2015, Mesozoic evolution of Colombia Central Cordillera: From extensional tectonics to volcanic arc settings: Medellín, Colombia, Universidad Nacional de Colombia,Thesis MSc, 1-48 p.

Zapata, S., Cardona, A., Jaramillo, J. S., Patiño, A., Valencia, V., León, S., Mejía, D., PardoTrujillo, A., Castaleda, J.P., 2018, Cretaceous extensional and compreessional tectonics in the Northwestern Andes, prior to the collision with the Caribbean oceanic plateau: Godwana Research, 66, 207-226. https:// doi.org/10.1016/j.gr.2018.10.008

Zapata, J., Correa, T., Obando, M., Rincón, A., Ortiz, F., Rodríguez, G., 2017, Redefinición cronoestratigráfica del Batolito de
Sabanalarga, en Congreso Colombiano de Geología 16 y Simposio de Exploradores, 3, Santa Marta, Colombia, 1472-1477.

Zapata-Villada, J.P., Restrepo, J.J., Cardona A., Martens, U., 2017, Geoquímica y geocronologíade las rocas volcánicas básicas y el gabro de Altamira, Cordillera Occidental(Colombia): registro de ambientes de Plateau y arco oceánico superpuestos durante el Cretácico. Boletín de Geología, 39 (2), 13-30. https://doi.org/10.18273/revbol. v39n2-2017001

Zapata-Villada, 2018, Registro magmático y metamórfico en una zona de colisión Cretácica en la margen occidental de la Cordillera Central: Implicaciones tectónicas en los Andes del Norte: Medellín, Colombia, Universidad Nacional de Colombia, Tesis de Maestría, 52p.

Zhang, Q., Guo, F., Zhao, L., Wu, Y., 2017, Geodynamics of divergent double subduction: 3-D numerical modeling of a Cenozoic example in the Molucca Sea region, Indonesia: 3-D numerical modeling of DDS: Journal of Geophysical Research: Solid Earth, 122 (5), 3977-3998. https://doi. org/10.1002/2017JB013991 
Anexo 1. Resultados isotópicos U-Pb en circones.
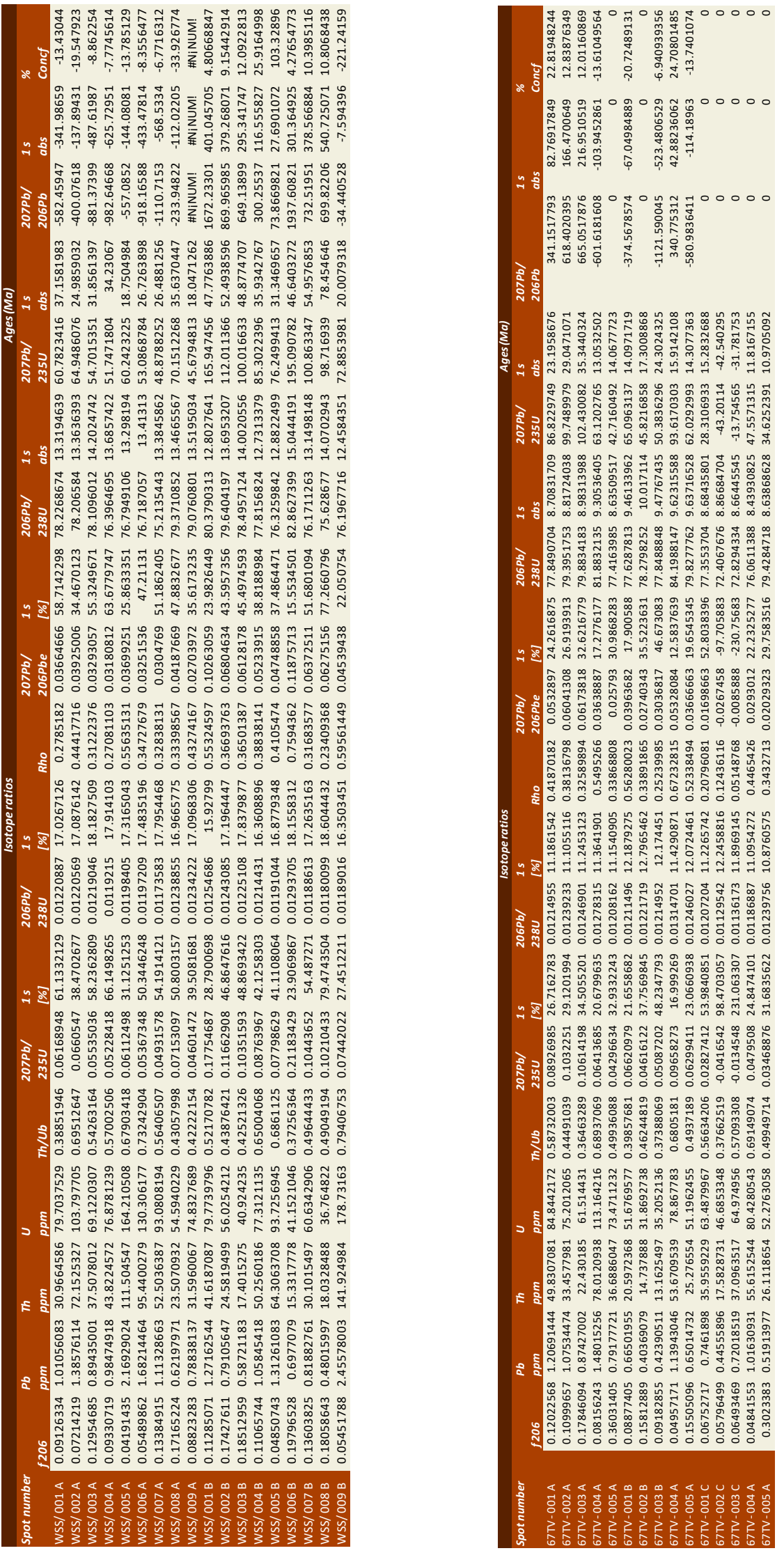


\section{Anexo 1. (Continuación) Resultados isotópicos U-Pb en circones.}
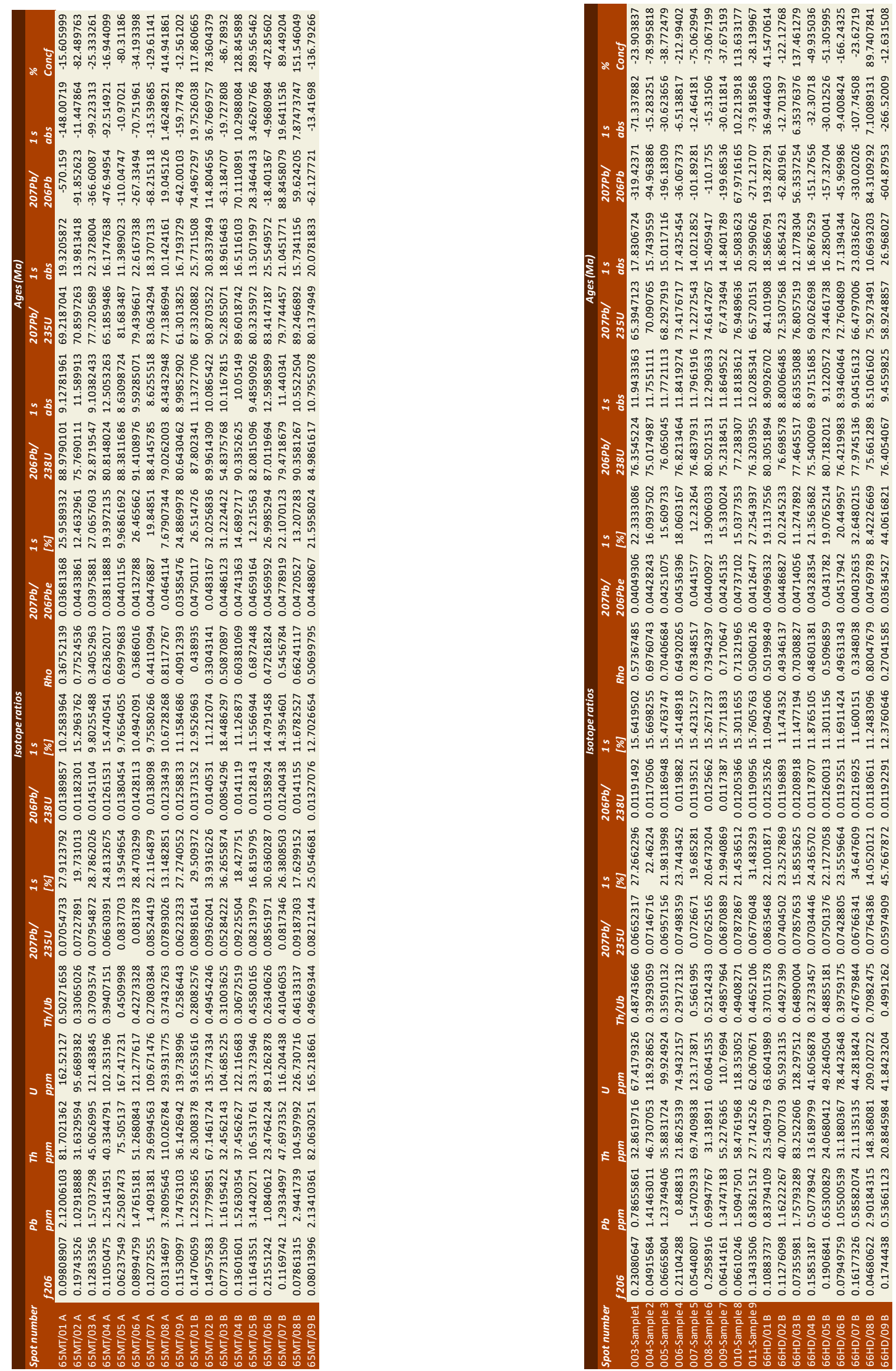


\section{Anexo 1. (Continuación) Resultados isotópicos U-Pb en circones.}

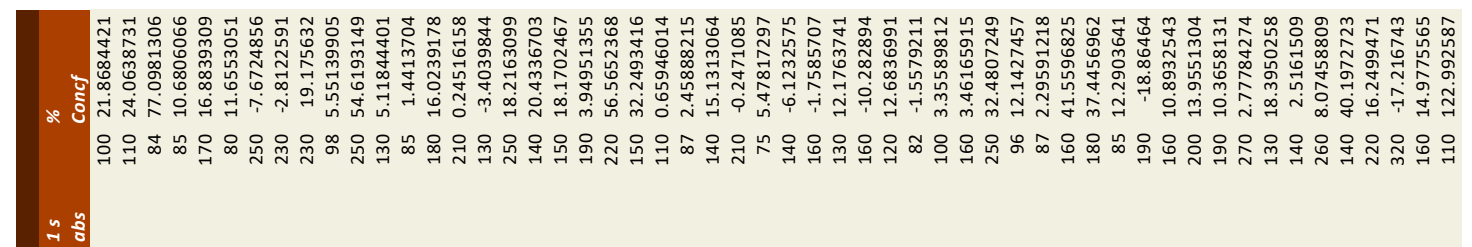

高高离

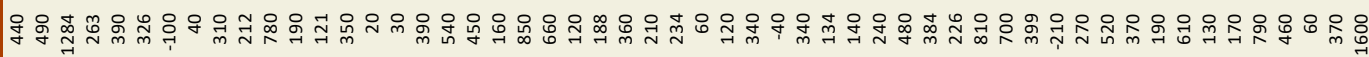

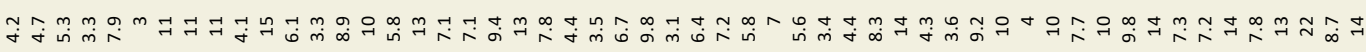

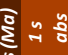

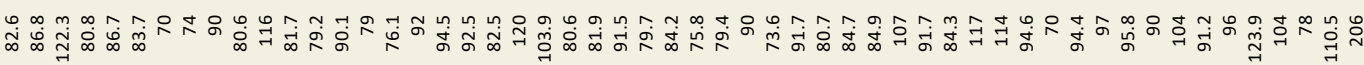

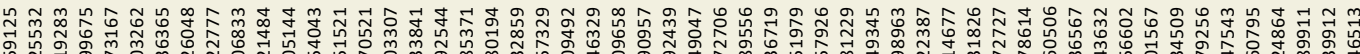

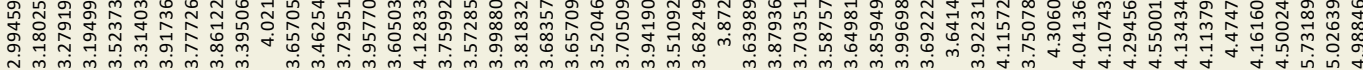

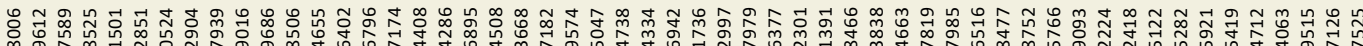

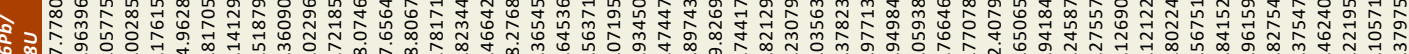

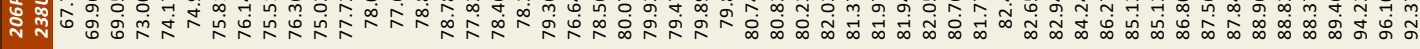
0
0

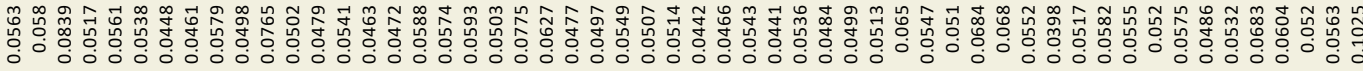
望

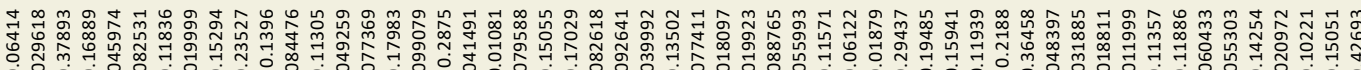

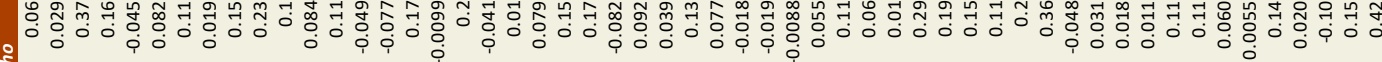

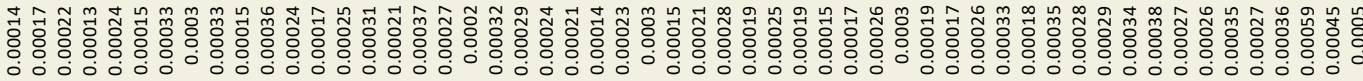

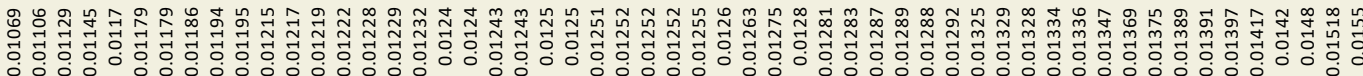

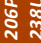

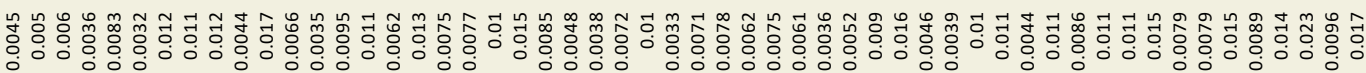
$\rightarrow$ 용

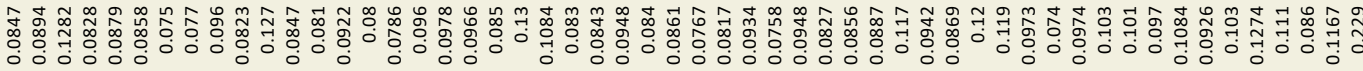

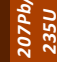

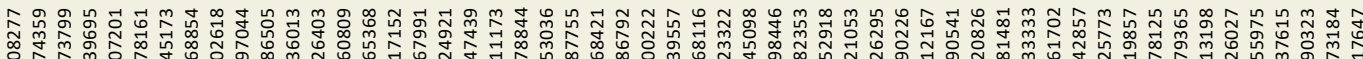

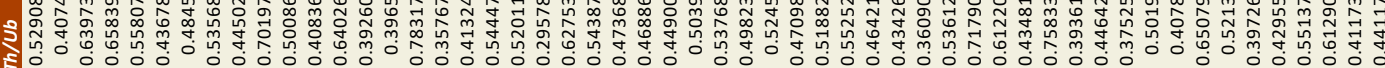

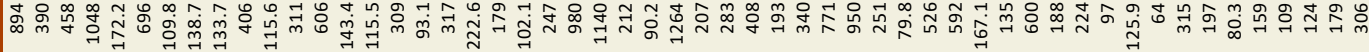

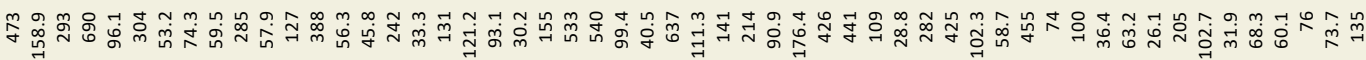




\section{Anexo 1. (Continuación) Resultados isotópicos U-Pb en circones.}

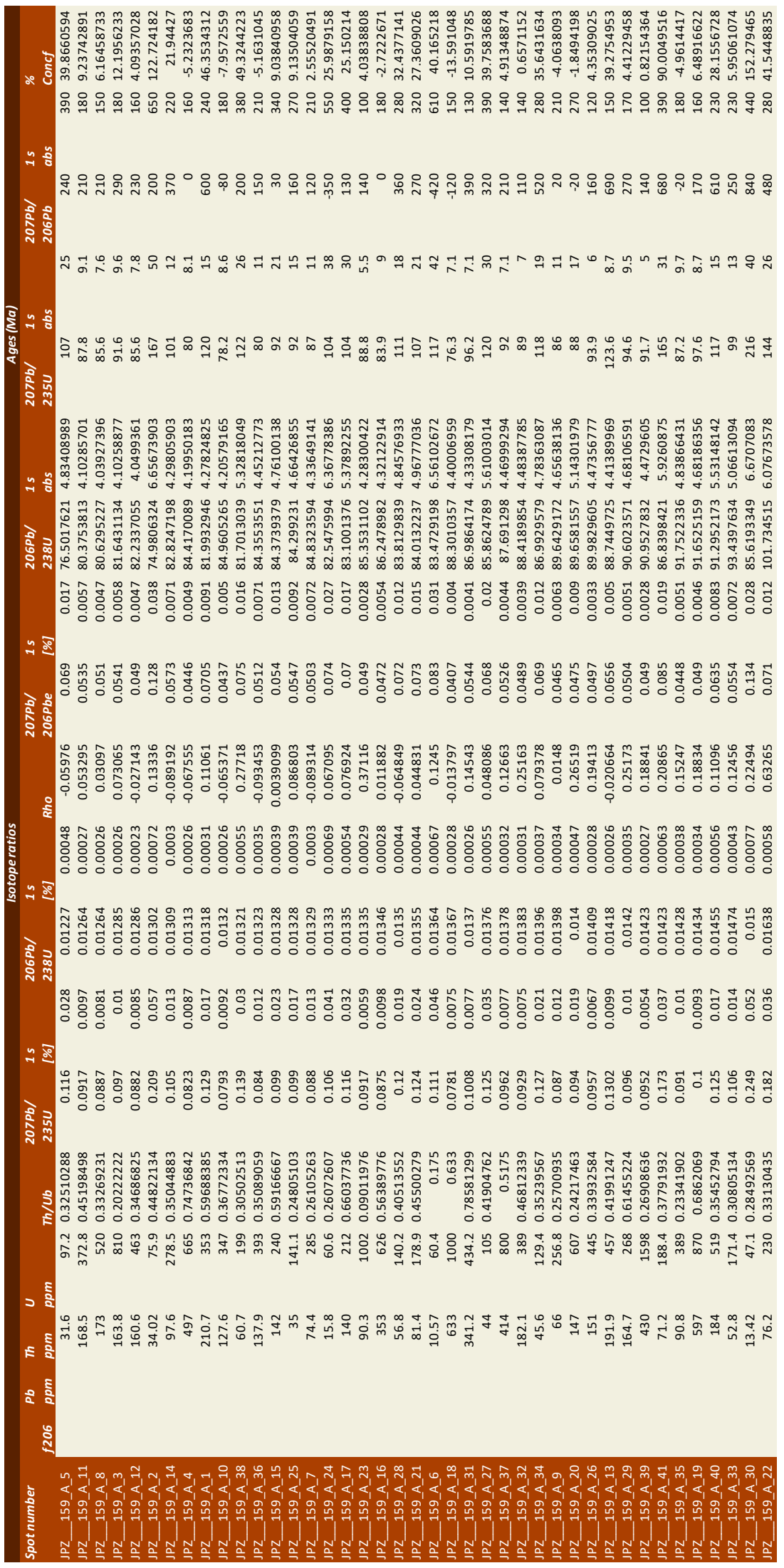




\section{Anexo 1. (Continuación) Resultados isotópicos U-Pb en circones.}

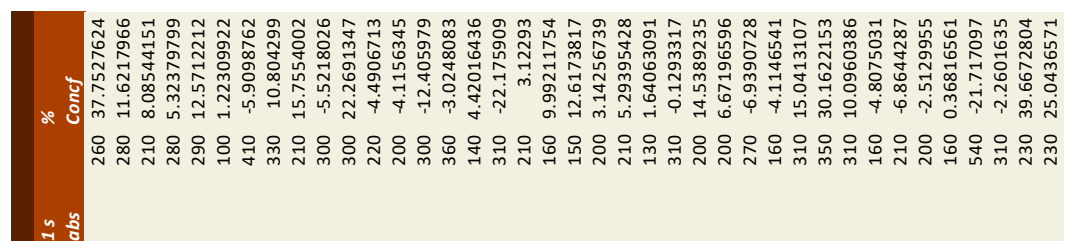

产高

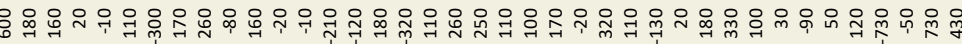

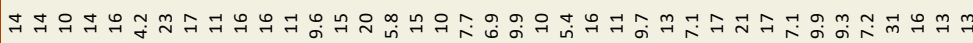

हृำ

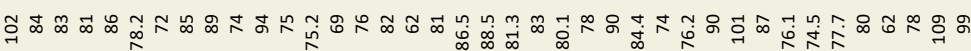
商

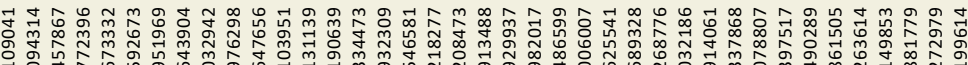

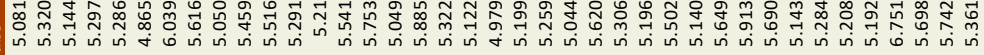

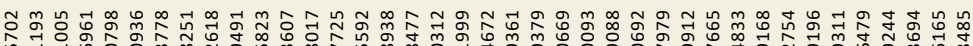

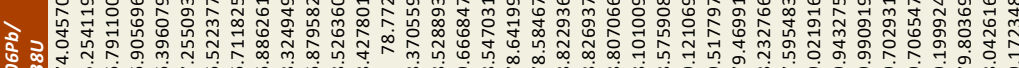

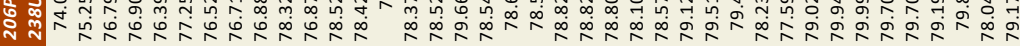

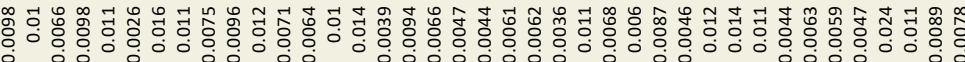
$\rightarrow$ 요

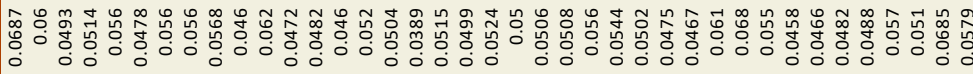
年

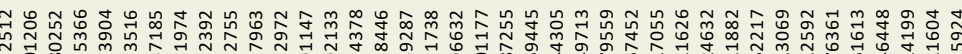

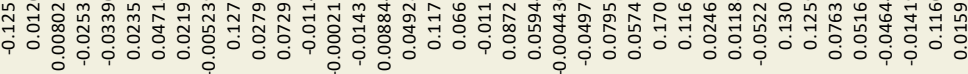

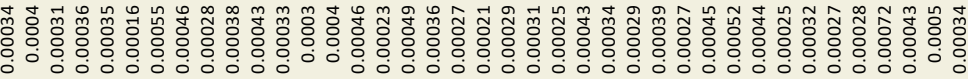

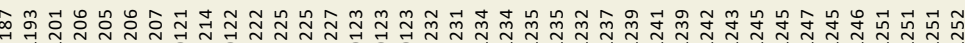

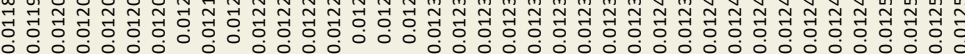

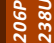

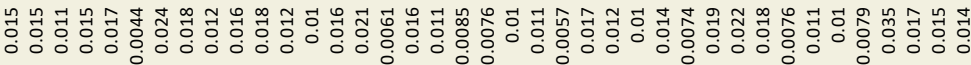
$\rightarrow$ बख्य

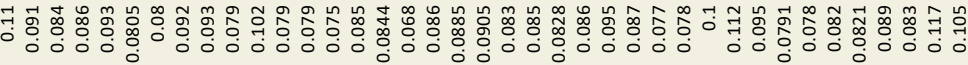
㠃

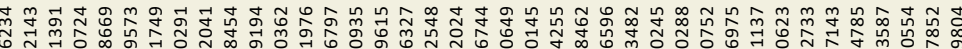

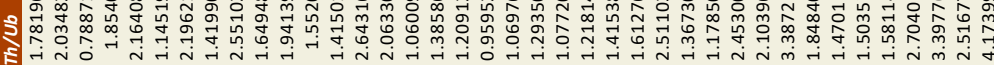

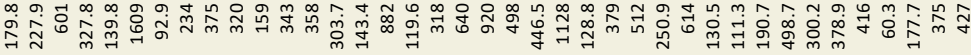
ว

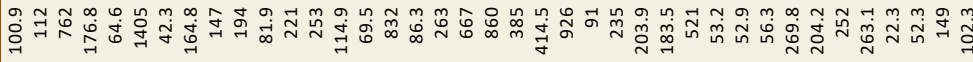

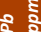




\section{Anexo 1. (Continuación) Resultados isotópicos U-Pb en circones.}

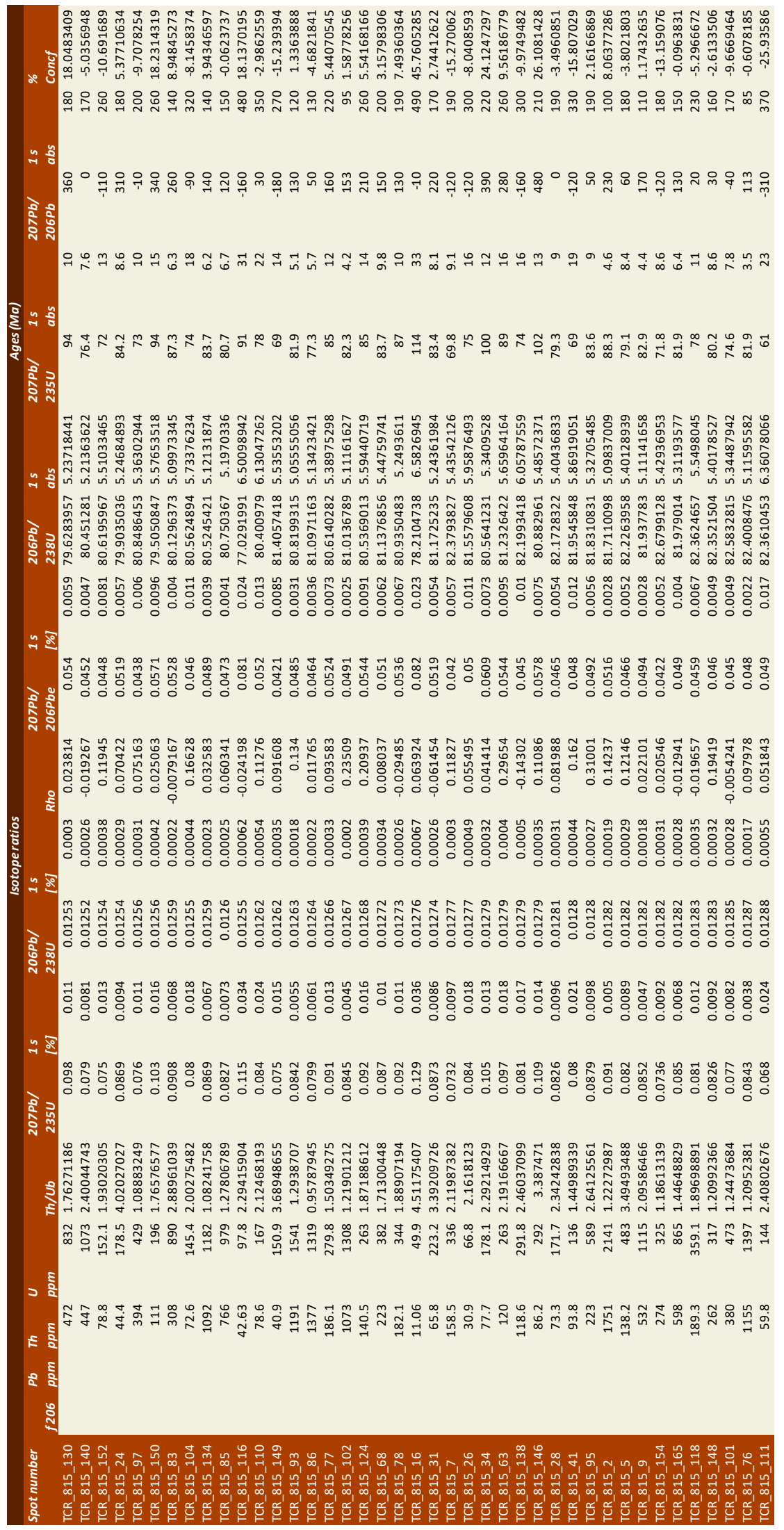




\section{Anexo 1. (Continuación) Resultados isotópicos U-Pb en circones.}

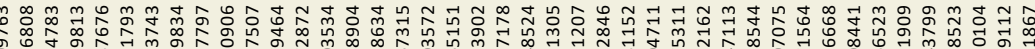

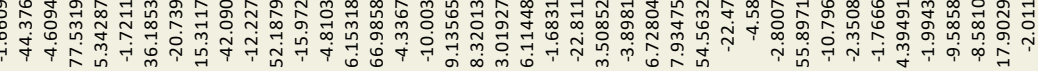

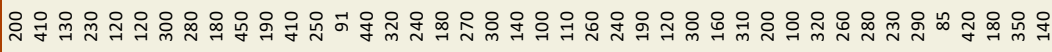

$\because \frac{4}{8}$

高高

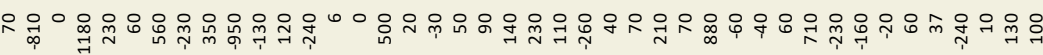

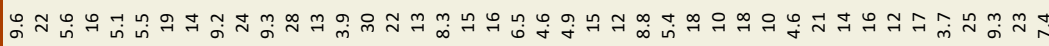

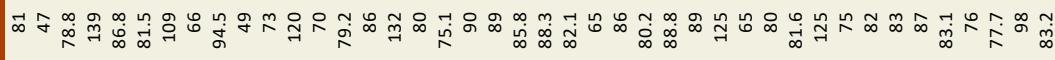

高赵

a

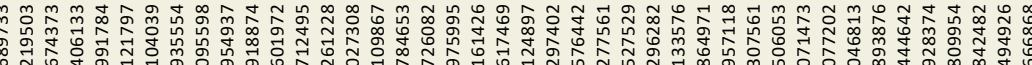

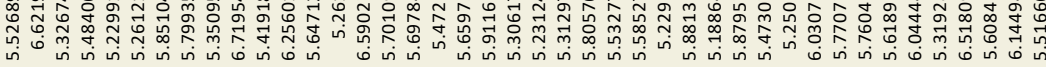

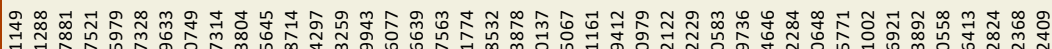

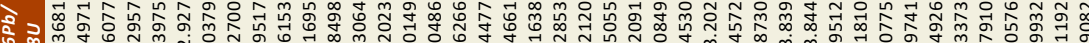

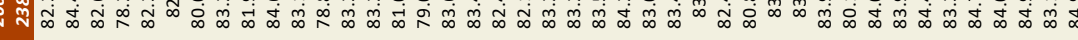

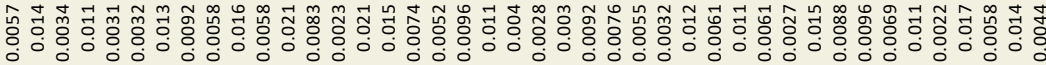

$\rightarrow$ ฮ 管

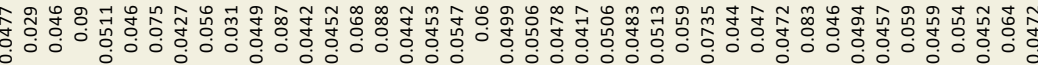

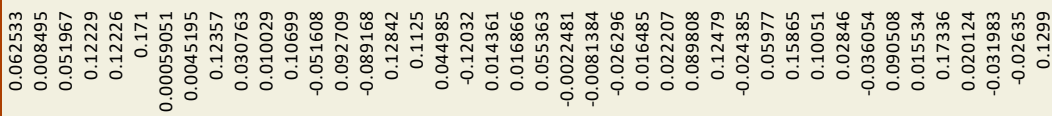

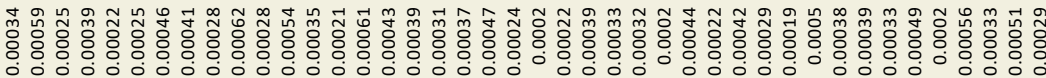
$\rightarrow$ 요

高文

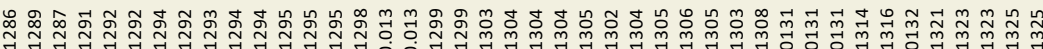

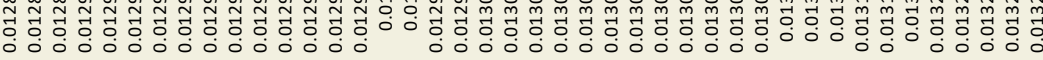

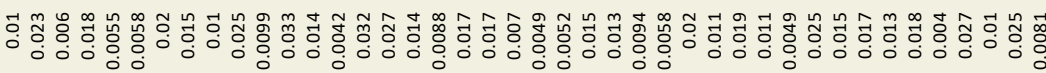
$\rightarrow$ 요

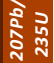

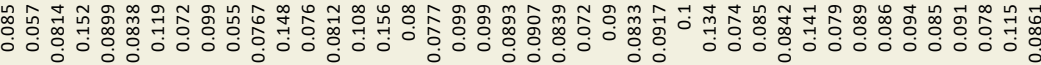

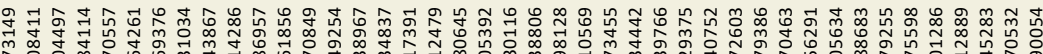

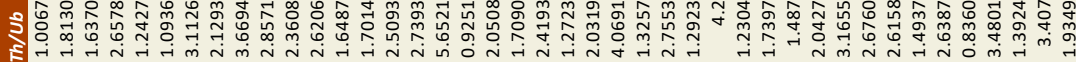

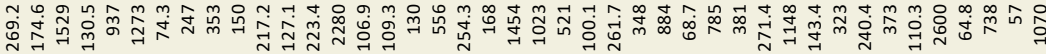

$>$ 言

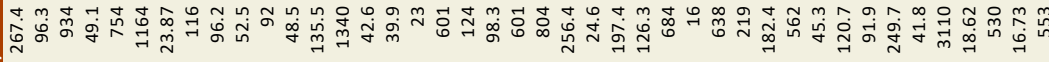

$\because$

帝

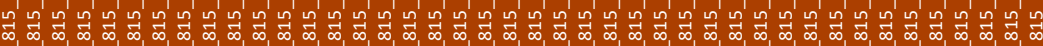

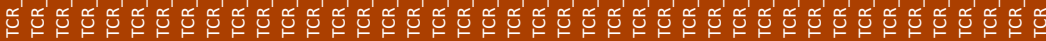




\section{Anexo 1. (Continuación) Resultados isotópicos U-Pb en circones.}

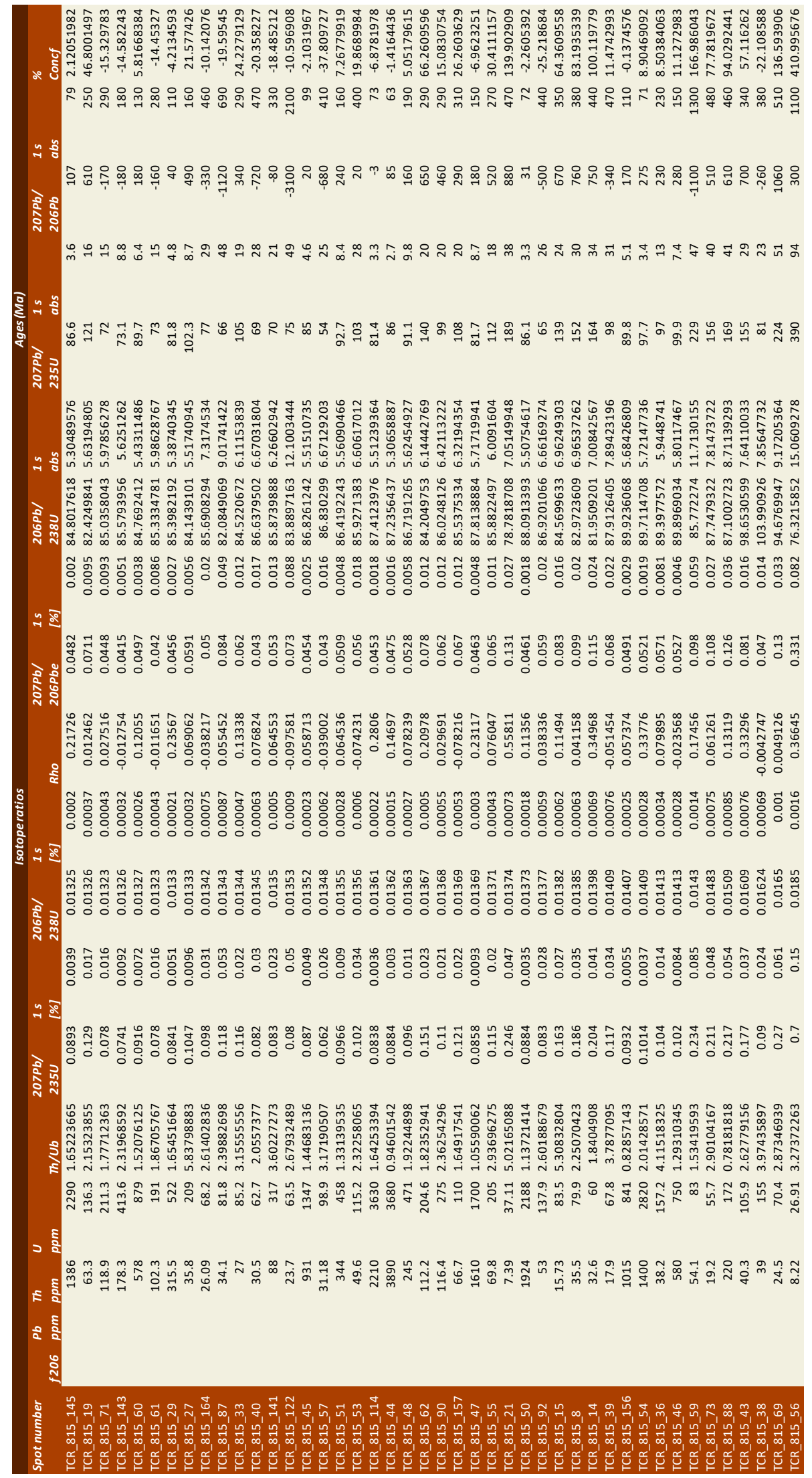


Anexo 1. (Continuación) Resultados isotópicos U-Pb en circones.
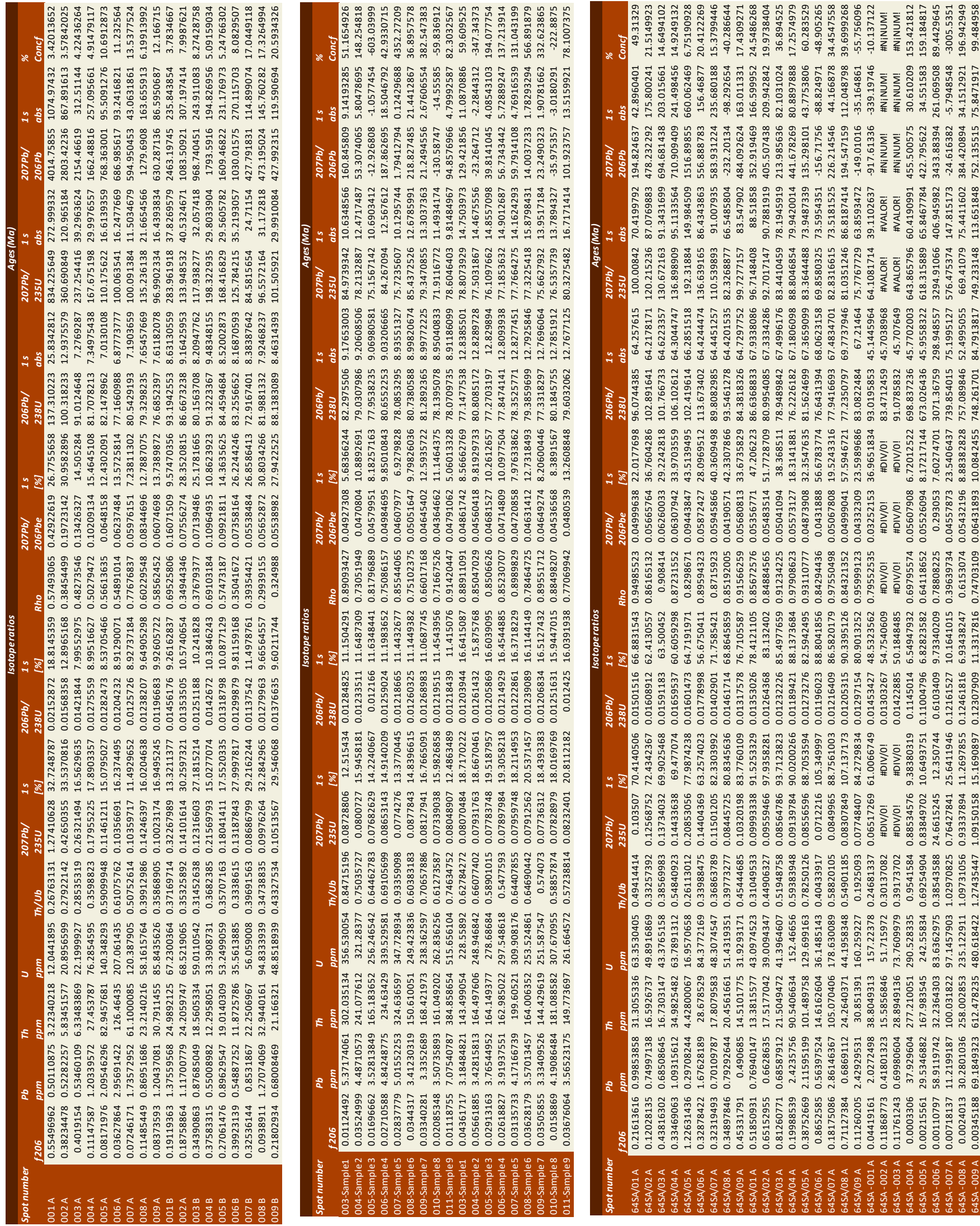
$\begin{array}{ll} & \\ 0 & \end{array}$

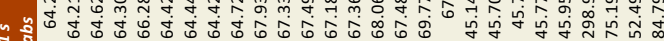

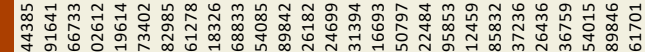

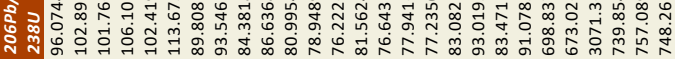

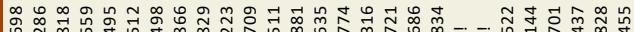
$\begin{array}{ll} & \\ 0 & \end{array}$

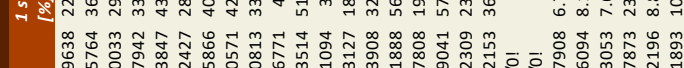

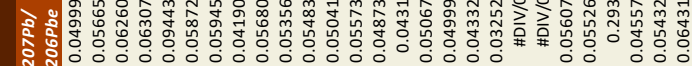

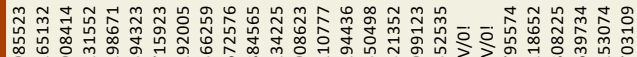

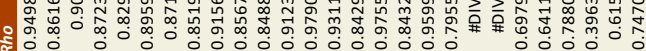

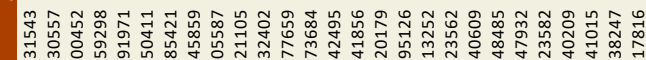

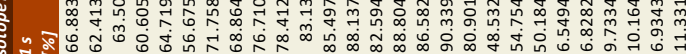
중

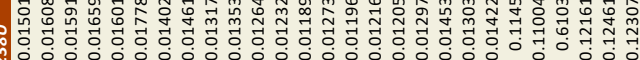

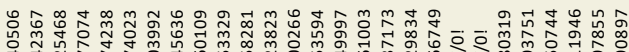

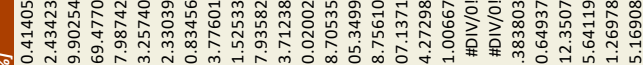

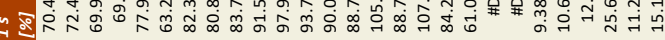

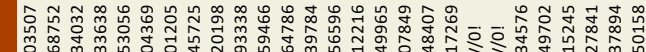

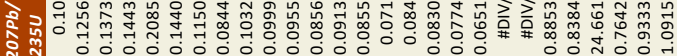

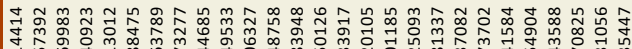

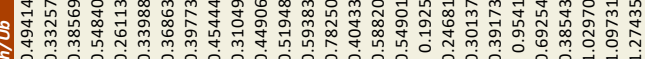

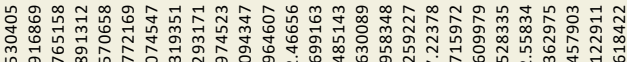

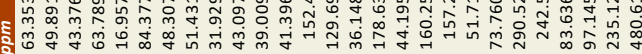

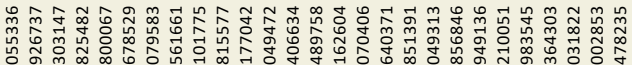
₹ $\infty$
$\infty$
$\infty$
$\infty$

\&

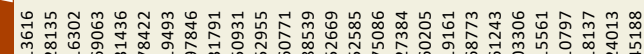

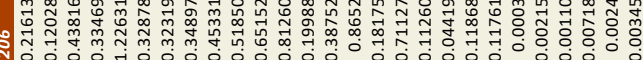
$\begin{array}{llll} & \\ 4\end{array}$ 


\section{Anexo 1. (Continuación) Resultados isotópicos U-Pb en circones.}

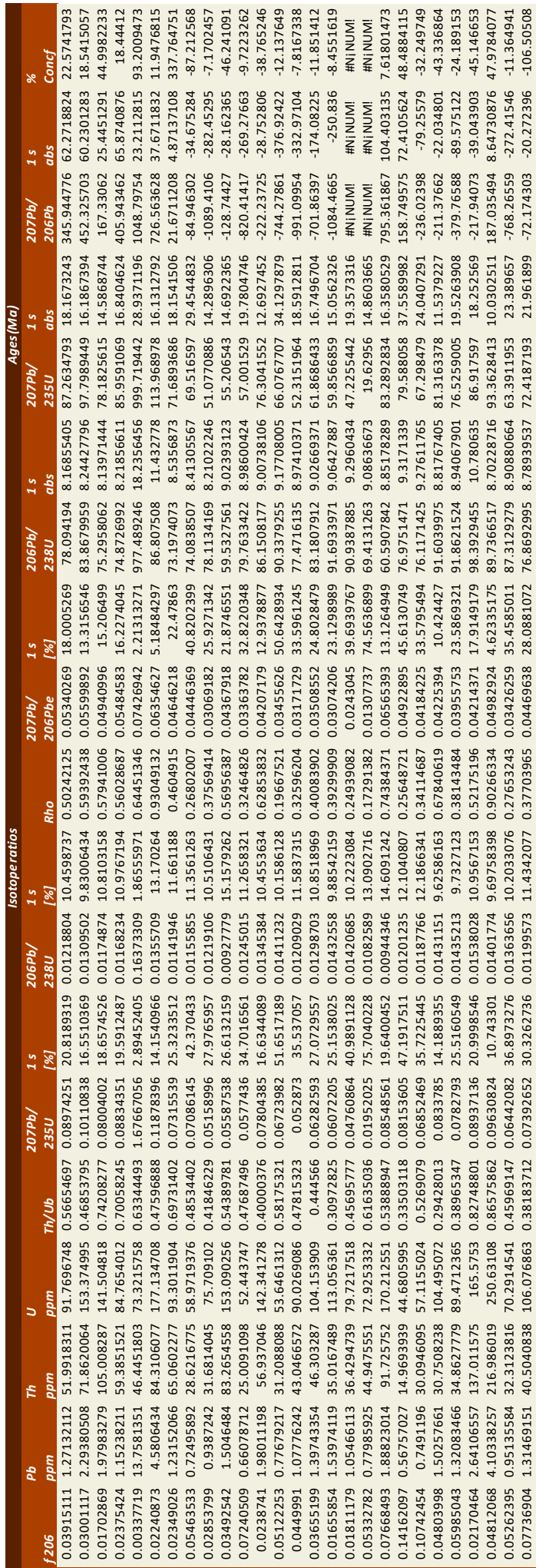

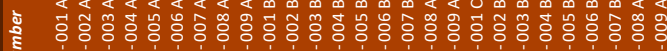

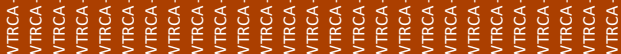

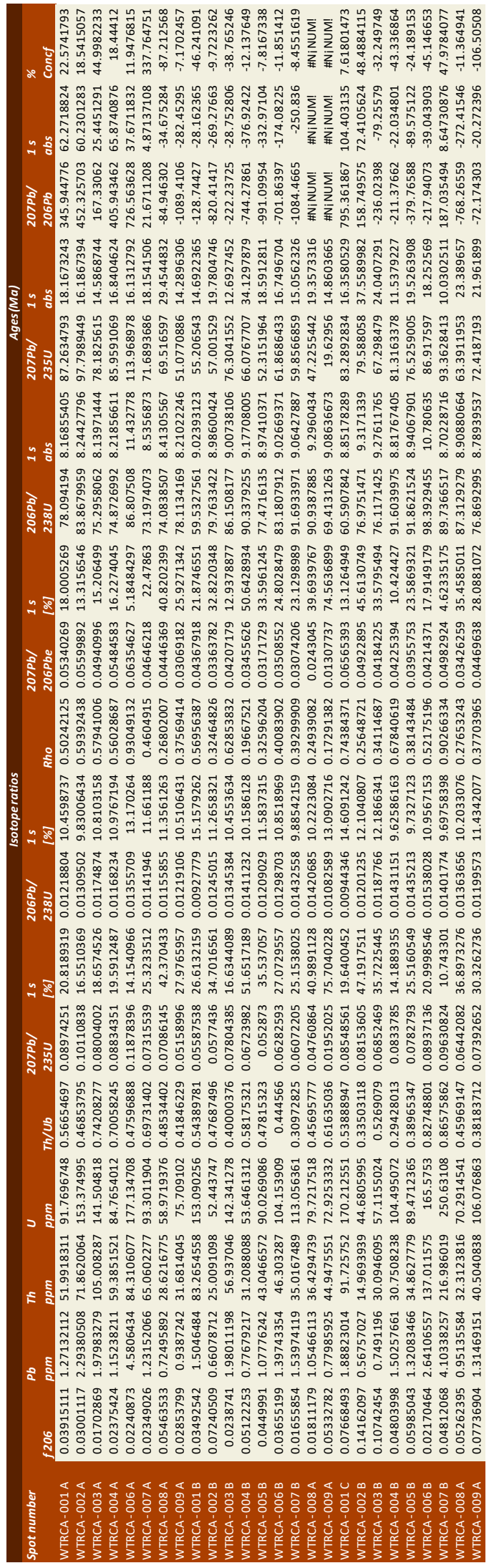


Anexo 1. (Continuación) Resultados isotópicos U-Pb en circones.
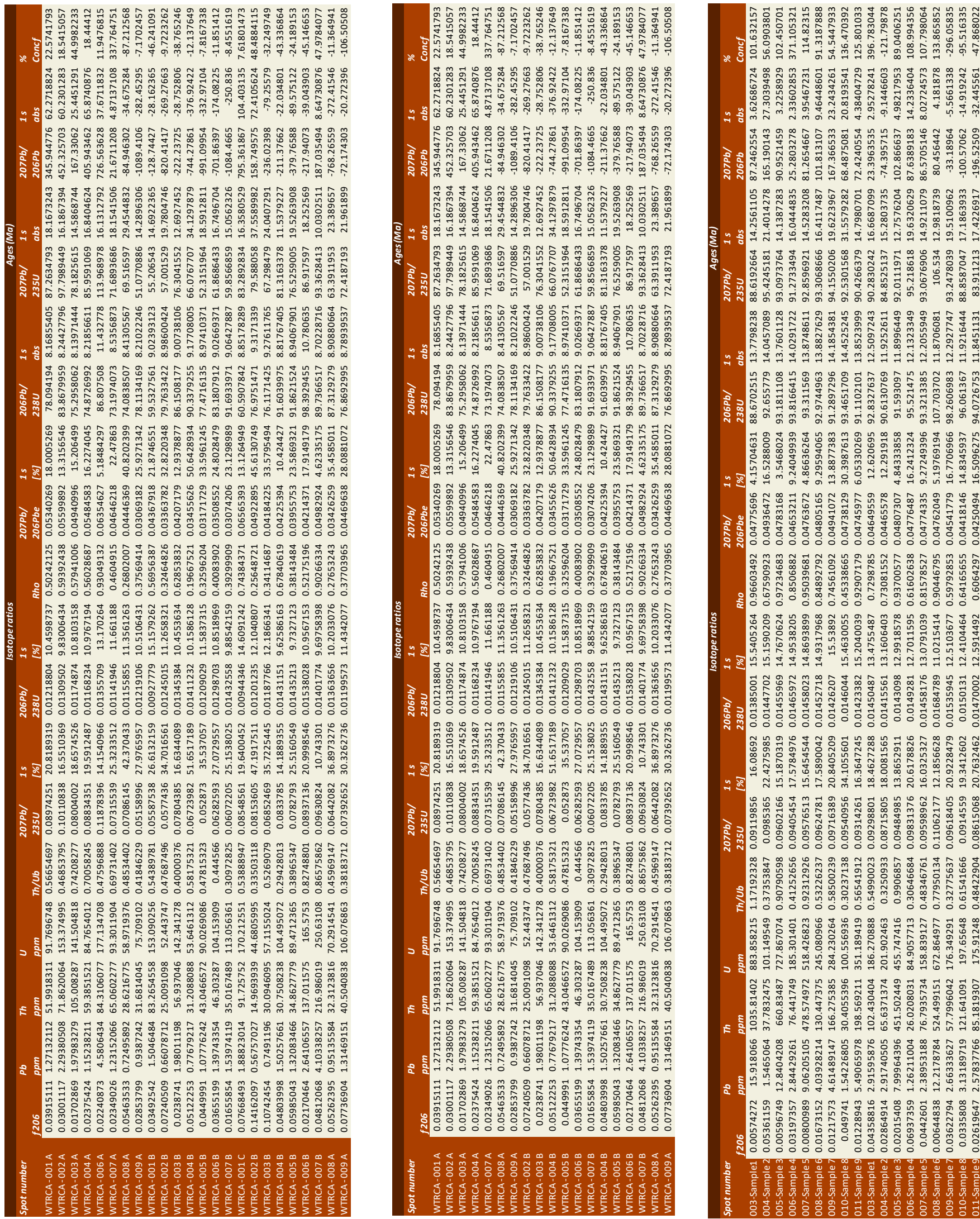

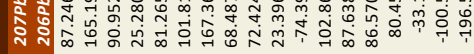

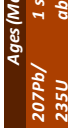

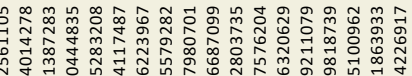

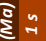

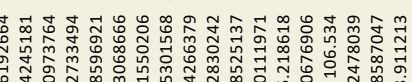

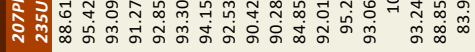

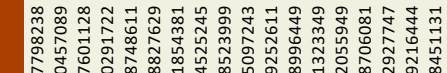

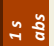

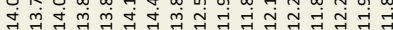

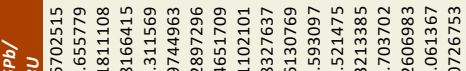

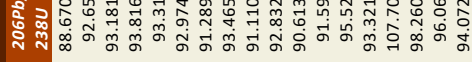

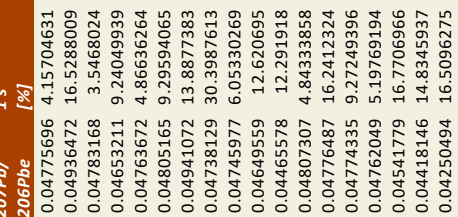

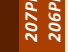

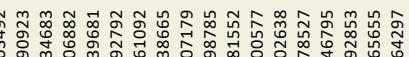

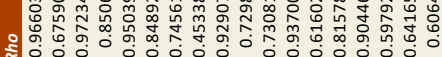

窟

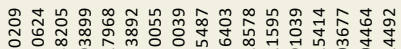

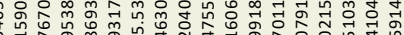

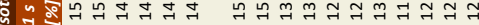

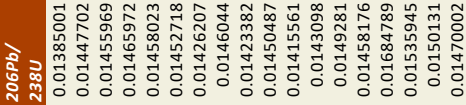

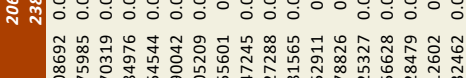

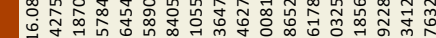

$\rightarrow$ 邹

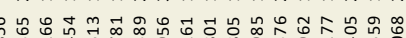

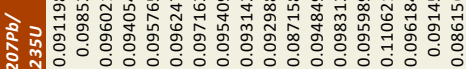

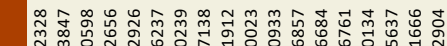

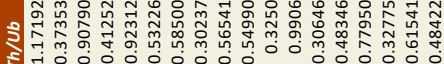

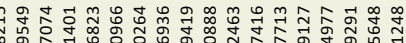

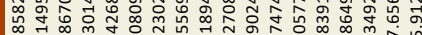

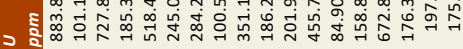

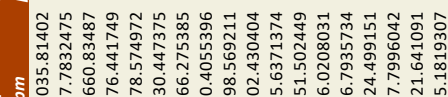

F 